\title{
EFFICIENT COMPETITIVE EQUILIBRIA WITH ADVERSE SELECTION
}

\author{
ALBERTO BISIN \\ PIERO GOTTARDI
}

CESIFO WORKING PAPER NO. 1504

CATEGORY 9: INDUSTRIAL ORGANISATION

JULY 2005
An electronic version of the paper may be downloaded
- from the SSRN website: WwW.SSRN.com
- from the CESifo website: www.CESifo.de




\title{
EFFICIENT COMPETITIVE EQUILIBRIA WITH ADVERSE SELECTION
}

\begin{abstract}
Do Walrasian markets function orderly in the presence of adverse selection? In particular, is their outcome efficient? This paper addresses these questions in the context of a Rothschild and Stiglitz insurance economy. We identify an externality associated with the presence of adverse selection as a special form of consumption externality. Consequently, we show that while competitive equilibria always exist, they are not typically incentive efficient. However, as markets for pollution rights can internalize environmental externalities, markets for consumption rights can be designed so as to internalize the consumption externality due to adverse selection. With such markets competitive equilibria exist and are always incentive efficient. Moreover, any incentive efficient allocation can be decentralized as a competitive equilibrium.
\end{abstract}

JEL Code: D82, D62, G22, D50.

Alberto Bisin
Department of Economics
New York University
269 Mercer Street
New York, NY10003
USA
alberto.bisin@nyu.edu

\author{
Piero Gottardi \\ Department of Economics \\ University of Venice \\ F.ta S. Giobbe \\ Cannaregio 873 \\ 30121 Venice \\ Italy \\ gottardi@unive.it
}

An earlier version of the paper circulated under the title 'Decentralizing Incentive Efficient Allocations of Economies with Adverse Selection'. We wish to thank Douglas Gale, Danilo Guaitoli, Atsushi Kajii, Ramon Marimon, Ed Prescott, Ilya Segal, Rob Townsend, Rajiv Vohra, and many seminar audiences for helpful comments. We are also grateful to Paolo Siconolfi and Aldo Rustichini for useful discussions which lead to the correction of a mistake in an earlier version of the paper, and to Onur Ozgur for help with the figures. Part of the work for this paper was carried out when the first author was visiting the Minneapolis Fed and IGIER, and when the second author was visiting Brown and NYU; we wish to thank the four institutions for their very kind hospitality. Finally, we owe greatly to Fernando Alvarez (the Editor) and three anonymous referees, who gave us truly exceptional and detailed comments. We benefited from the technical and financial support of the C.V. Starr Center for Applied Economics, the financial support from the NSF grant SES-9818844 to the first author and from a grant from MIUR to the second author. 


\section{Introduction and Motivation}

We study competitive exchange economies with adverse selection. Agents have private information regarding the probability distribution of their endowments. Firms offer trade contracts providing the agents with insurance against the realization of their individual idiosyncratic uncertainty. Agents' trades can be fully monitored, so that firms can enforce exclusive contractual relationships. ${ }^{1}$ The agents' private information is then the only 'friction' to the operation of markets. We analyze Walrasian equilibria where both consumers and firms act as price takers.

We intend to address the following questions: Do Walrasian markets function orderly in the presence of adverse selection? What are the properties of allocations attainable as Walrasian equilibria of economies with adverse selection and exclusive contracts? And in particular, Are Walrasian equilibria incentive efficient?

Our analysis is motivated by the fundamental contribution of Prescott and Townsend (1984), (1984b). They analyze Walrasian equilibria of economies with moral hazard and with adverse selection when exclusive contracts are enforceable. While for moral hazard economies they prove existence and constrained versions of the first and second theorems of welfare economics, ${ }^{2}$ they show that their approach cannot be successfully extended to adverse selection economies. They conclude (p. 44) that "there do seem to be fundamental problems for the operation of competitive markets for economies or situations which suffer from adverse selection."

In this paper we identify first a special form of consumption externality which arises in economies with adverse selection and exclusive contracts: the level of trades chosen by agents of one type influences, via its effect on the incentive compatibility constraints, the admissible trades of agents of other types. In the spirit of the approach pioneered by Arrow (1969) and Lindahl (1919) to the study of economies with externalities, we then show that the introduction of appropriate markets for consumption rights allows agents to internalize the externality induced by adverse selection and results therefore in incentive efficient competitive equilibrium allocations.

In economies with environmental externalities, efficient allocations can be decentralized by requiring that firms do not produce unless they acquire the appropriate amount of "pollution rights", which are traded in the market at competitive prices. Similarly, in the adverse selection economies we consider, the decentralization of incentive efficient allocations requires that agents do not consume unless they acquire the appropriate amount of "consumption rights". This link between the level of consumption and holdings of

\footnotetext{
${ }^{1}$ Exclusivity is clearly a strong assumption. It is nonetheless the benchmark case considered in contract theory as well as in general equilibrium analyses of economies with asymmetric information, e.g., in Prescott-Townsend (1984). The properties of competitive equilibria when this condition is violated and only non-exclusive contractual relationships are available are investigated in Bisin-Gottardi (1999).

${ }^{2}$ See also Bennardo-Chiappori (2003), Kehoe, Levine and Prescott (2002), and Kocherlakota (1998).
} 
rights induces agents to internalize the externality their own consumption imposes on the economy in the presence of adverse selection. For instance, a higher level of consumption by agents of a low risk type might exert a negative externality on agents of a high risk type by tightening their incentive constraint. That is, a higher consumption level by the low risk agents renders a higher level of consumption by the high risk agents necessary to guarantee that they do not misreport their risk type and choose to consume the same amount of the low risk agents. The low risk types will internalize this externality because at equilibrium they will have to buy, at a positive price, an amount of consumption rights which appropriately increases with their own consumption level.

We call Walrasian equilibria with such market structure ALPT, for Arrow-LindahlPrescott-Townsend. This expanded structure of markets allows to fully decentralize incentive efficient allocations. We show that ALPT equilibria exist and incentive constrained versions of the first and second theorem of welfare economics hold. In other words, we successfully replicate for adverse selection economies the results that PrescottTownsend (1984),(1984b) obtain for moral hazard economies, thereby offering a solution to the problem their papers opened.

Evidently, the implementation of the structure of markets which guarantees the decentralization of incentive constrained efficient allocations in adverse selection economies requires an enforcement mechanism which prevents agents from acquiring commodities for their own consumption without acquiring also the appropriate amount of consumption rights. However, we will argue that the implementation of markets for consumption rights can be greatly simplified by designing an enforcement mechanism which operates on insurance firms rather than directly on agents and by having consumption rights take the simple form of the 'right' to trade in the market designated for the 'low risk' agents. At equilibrium firms offering contracts exclusively to 'low risks' would acquire the 'right' to do so from 'high risk' agents at market-determined prices. When at equilibrium the prices of the rights are positive an efficient allocation is decentralized at which 'low risks' subsidize 'high risks' by compensating them for selling their 'rights' to trade in the 'low risk' insurance market.

We also consider economies where the markets for consumption rights are not available. In this case, each agent is only able to trade claims to his own consumption. He has then to satisfy the incentive compatibility constraints with respect to the level of trades chosen by the other types of agents, taken as given. We call Walrasian equilibria with such structure of markets EPT, for Prescott-Townsend with externality. There are no fundamental problems associated with this Walrasian equilibrium concept either. We show that an EPT equilibrium always exists and provides a useful - and somewhat robust - prediction to the outcome of competitive markets in such economies. Evidently, EPT equilibria are not ensured to be incentive efficient. However, they satisfy an appropriately defined notion of third best efficiency and the second welfare theorem also holds for this equilibrium concept.

The analysis of this paper is developed for a simple insurance economy with adverse 
selection as the one considered by Rothschild and Stiglitz (1976). This constitutes a very important test case for any equilibrium notion for adverse selection economies. In addition, by exploiting the simple structure of the economy, we are able to clearly illustrate the features and to provide a complete characterization of the various notions of Walrasian equilibrium which we study. In particular, the allocation we obtain as unique EPT equilibrium corresponds to the Rothschild-Stiglitz separating candidate equilibrium (this is so even for those parameter values for which Rothschild-Stiglitz (1976) found non-existence). On the other hand, ALPT equilibria might entail a nonzero level of cross-subsidization, i.e., some degree of 'pooling' among types.

The paper is organized as follows. The structure of the economy is presented in the next section; incentive efficient allocations are then characterized in Section 3. In Section 4, first EPT equilibria and then ALPT equilibria are defined, their existence established, and their efficiency properties characterized. The proofs of the main results are collected in the Appendix. ${ }^{3}$

\section{The Economy}

Consider an economy with adverse selection populated by a continuum of agents of two different types, $b$ and $g$. Let $\xi^{b}$ denote the fraction of agents of type $b$ and $\xi^{g}$ the fraction of agents of type $g$ in the population. We assume $\xi^{b}, \xi^{g}>0$.

There is a single consumption good. Uncertainty enters the economy via the level of the agents' endowment and is purely idiosyncratic. There are two possible states, $H, L$, for every individual, and his endowment when $H$ (resp. $L)$ is realized is $\omega_{H}\left(\operatorname{resp} . \omega_{L}\right)$. Let $\pi_{s}^{i}$ be the probability that individual state $s \in S \equiv\{H, L\}$ is realized for an agent of type $i \in\{g, b\}$. These random variables are independently distributed across all agents and identically distributed across agents of the same type.

Each agent is privately informed about his type. On the other hand, the realization of individual states is commonly observed.

With no loss of generality, let $\omega_{L}<\omega_{H}$ and $0<\pi_{H}^{b}<\pi_{H}^{g}<1$. It follows that state $H$ corresponds to a high endowment realization and type $b$ is the 'high-risk' type.

The preferences of each agent are described by a von Neumann-Morgernstern utility function with type independent utility index $u: \mathbb{R}_{+} \rightarrow \mathbb{R}_{+}$defined over consumption in each idiosyncratic state $s \in S$. Let then $U^{i}\left(x^{i}\right) \equiv \sum_{s \in S} \pi_{s}^{i} u\left(x_{s}^{i}\right)$, for $i \in\{g, b\}$, where $x^{i} \equiv\left(x_{H}^{i}, x_{L}^{i}\right)$.

We assume:

Assumption 1. Endowments are always strictly positive for all agents: $\omega_{L}, \omega_{H}>0$.

\footnotetext{
${ }^{3} \mathrm{~A}$ complete presentation of the proofs of all other results in the paper, as well as some additional discussions of our results, can be found in Bisin and Gottardi (2005).
} 
Preferences are strictly monotonic, strictly concave, twice continuously differentiable, and $\lim _{x \rightarrow 0} u^{\prime}(x)=\infty$.

Note that the economy is the same as the insurance economy with adverse selection considered by Rothschild and Stiglitz (1976).

\section{Incentive Efficient Allocations}

Let $\omega \equiv\left\{\omega_{H}, \omega_{L}\right\} \in \mathbb{R}_{+}^{2} \cdot z^{i} \equiv\left(z_{H}^{i}, z_{L}^{i}\right) \in \mathbb{R}^{2}$ denotes then the net transfers in each state to type $i \in\{g, b\}$. The consumption level induced by such transfers is $x^{i}=\omega+z^{i}$. A (symmetric) feasible allocation is then described by a pair of net transfers $\left\{z^{g}, z^{b}\right\}$ satisfying the following resource feasibility constraint:

$$
\sum_{s \in S}\left(\xi^{g} \pi_{s}^{g} z_{s}^{g}+\xi^{b} \pi_{s}^{b} z_{s}^{b}\right) \leq 0
$$

where the purely idiosyncratic nature of the uncertainty and the Law of Large Numbers have been used to take the sum of the net transfers of the commodity contingent on each individual state, weighted by their probability.

An incentive compatible allocation is a pair $\left\{z^{g}, z^{b}\right\}$ which satisfies the following constraints:

$$
\begin{aligned}
& \sum_{s \in S} \pi_{s}^{g} u\left(\omega_{s}+z_{s}^{g}\right) \geq \sum_{s \in S} \pi_{s}^{g} u\left(\omega_{s}+z_{s}^{b}\right) \\
& \sum_{s \in S} \pi_{s}^{b} u\left(\omega_{s}+z_{s}^{b}\right) \geq \sum_{s \in S} \pi_{s}^{b} u\left(\omega_{s}+z_{s}^{g}\right)
\end{aligned}
$$

Definition 1 An allocation $\left\{z^{g}, z^{b}\right\}$ is incentive efficient it is feasible, incentive compatible (i.e., satisfies ((1-3)) and if there does not exist another allocation $\left\{\hat{z}^{g}, \hat{z}^{b}\right\}$, also feasible and incentive compatible, such that $U^{b}\left(\omega+\hat{z}^{b}\right) \geqslant U^{b}\left(\omega+z^{b}\right)$ and $U^{g}\left(\omega+\hat{z}^{g}\right) \geqslant$ $U^{g}\left(\omega+z^{g}\right)$, with at least one inequality being strict. ${ }^{4}$

For the simple adverse selection economy under consideration, Prescott and Townsend (1984) have provided a complete characterization of the set of incentive efficient consumption allocations. ${ }^{5}$ At any incentive efficient allocation at least one of the two types

\footnotetext{
${ }^{4}$ As shown by Prescott and Townsend (1984) (see, also, Cole (1989)), in the presence of asymmetric information it may be desirable to expand the commodity space so as to allow for random allocations of contingent commodities, or lotteries over consumption bundles. This is not the case for our simple adverse selection economy, for which allocations involving nondegenerate lotteries are always suboptimal (see Prescott and Townsend (1984)). To keep the notation simpler, definitions are then stated for the case of non random allocations.
}

${ }^{5}$ See also Crocker and Snow (1985) and Jerez (2003). 
of agents' is fully insured (has a deterministic consumption bundle). Incentive efficient allocations can then be classified according to which type of agent is fully insured.

Consider first the incentive efficient allocations where the agents of type $b$ are fully insured. At such allocations the type $g$ agents are only partially insured, that is, their consumption is higher in state $H$ than in state $L$. The level of insurance provided to agents of type $g$ is in fact limited by the incentive constraint requiring that agents of type $b$ prefer $z^{b}$ to $z^{g}$, as in (3) above. Agents of type $b$ are instead fully insured because the other incentive constraint is not binding. Allocations in this class can be parameterized by the level of consumption of type $b$ agents, or equivalently by the expected value of the net transfer they receive, on a per capita basis, given by $\sum_{s \in S} \pi_{s}^{b} z_{s}^{b}$. The allocation obtained when the expected net transfer to agents of type $b$ is zero is the separating allocation induced by Rothschild and Stiglitz separating pair of contracts, illustrated in Figure 1.

The minimum level of the expected net transfer to type $b$ agents which is compatible with incentive efficiency may turn out to be strictly positive. This occurs in particular when the fraction $\xi^{g}$ of agents of type $g$ is large enough. In this case the Rothschild and Stiglitz separating allocation is not incentive efficient: the utility of type $g$ agents is increased if they make a positive subsidy to type $b$ 's consumption, as the subsidy relaxes their binding incentive constraint and this more than compensates the cost of the subsidy.

At incentive efficient allocations where the agents of type $b$ are fully insured, the higher is the expected value of the net transfer to agents of type $b$, the weaker is the incentive constraint (3), and hence the greater the amount of insurance that can be provided to agents of type $g$. There exists then also a maximum level of the expected net transfer compatible with the incentive efficiency of allocations in this class, at which (3) becomes non binding. At the allocation corresponding to this level both types of agents are fully insured and consume the same amount. This is the pooling allocation induced by Rothschild and Stiglitz pooling contract, illustrated in Figure 2. No incentive constraint binds at this allocation, and Pareto efficiency also obtains.

The second class of incentive efficient allocations has the property that type $g$ agents are fully insured. Agents of type $b$ are then overinsured, that is, their consumption is higher in state $L$. The extent by which this happens is determined by the incentive constraint requiring that agents of type $g$ prefer $z^{g}$ to $z^{b}$, as in (2). The characterization of incentive efficient allocations when agents of type $g$ are fully insured is symmetric to the characterization obtained above when agents of type $b$ are fully insured. Allocations can now be parameterized by the per capita level of the expected net transfer type $g$ agents receive, given by $\sum_{s \in S} \pi_{s}^{g} z_{s}^{g}$.

As in Rothschild and Stiglitz, the pooling and the separating allocations will play a central role in our analysis. 


\section{$4 \quad$ Walrasian Equilibria}

Various competitive equilibrium concepts have been used in the analysis of adverse selection economies with exclusive contracts. The standard strategic analysis of such economies, due to Rothschild and Stiglitz (1976), considers the Nash equilibria of a game in which insurance companies simultaneously choose the contracts they issue. The competitive aspect of the equilibrium is captured by allowing the free entry of insurance firms. (Different specifications of the game among insurance companies, for instance where dynamic reactions to new contract offers are allowed, have been considered in the literature e.g., by Wilson (1977), Riley (1979), Hellwig (1987); see also Maskin and Tirole (1992).)

Our approach consists instead in studying Walrasian equilibrium concepts, where both agents and insurance firms act as price takers in competitive markets. At equilibrium a price is quoted for all possible contracts. We consider the case where agents' trades are fully observable, so that exclusive contracts can be implemented. Following the approach used by Prescott and Townsend (1984) for moral hazard economies, we model exclusivity of contracts by imposing incentive compatibility directly as a constraint on the set of admissible trades of every agent. Prices are then indexed by the agent's declared type and linear over such restricted domain. ${ }^{6}$

Differently from the case of moral hazard economies, with adverse selection each incentive compatibility constraint relates the consumption levels of the two types of agents. As we see from (2-3), when agents of one type vary their consumption, this affects the set of values of consumption of the other type that satisfies incentive compatibility. Thus, when the incentive compatibility constraints are imposed the set of contracts that agents of one type can trade depends on the trades of the agents of the other type: an externality arises in the specification of the set of admissible trades of each agent.

Our first contribution is to show that once the presence and the nature of the externality in adverse selection economies with exclusive contracts is clearly identified, Walrasian equilibria can be defined and their properties analyzed as in other competitive economies with externalities in consumption.

We will consider first the notion of EPT equilibrium, where each agent takes as given the level of trades made by the other types, i.e. the externality is not internalized. Next, the notion of ALPT equilibrium will be examined, where markets allowing to internalize the externality are introduced. We will show that, in contrast to the strategic approach by Rothschild and Stiglitz, Walrasian equilibria always exist. We will also characterize equilibrium allocations and study their welfare properties.

\footnotetext{
${ }^{6}$ An alternative way of modeling exclusive contractual relationships consists in allowing for non-linear price schedules for contracts. In this case suitable 'refinements' restricting admissible equilibrium prices are necessary to select between the large set of equilibria one obtains; see Gale (1992), (1996) and Dubey, Geanakoplos, Shubik (1995).
} 


\subsection{EPT Equilibria}

Each agent can trade, at linear prices, claims contingent on the realization of his individual uncertainty as well as on his declared type. Let $q_{i, s} \in \mathbb{R}_{+}$be the unit price at which any agent who claims to be of type $i \in\{g, b\}$ can trade the consumption good for delivery in his individual state $s \in S, \mathbf{q} \equiv\left\{q_{g, H}, q_{g, L}, q_{b, H}, q_{b, L}\right\} \in \mathbb{R}_{+}^{4}$. To fix notation, note that here and in what follows a subscript $i \in\{g, b\}$ denotes the type declared by the agent, while a superscript denotes his actual unobservable type.

The set of admissible trades in such markets is restricted then by imposing incentive compatibility constraints. More precisely, the specification of the set of admissible trades of every agent is constructed as follows. The agent has to choose a vector $\mathbf{z} \equiv\left\{z_{g}, z_{b}\right\} \in$ $\mathbb{R}^{4}$, where $z_{i} \equiv\left\{z_{i, H}, z_{i, L}\right\}$ denotes the net trades made in the market where agents who declare to be of type $i \in\{g, b\}$ trade. Every agent can claim to be of type $g$ and trade in the market designated for the type $g$ at the prices $q_{g}$ ). Alternatively, he can claim to be of type $b$ and trade in the market designated for $b$ at the prices $q_{b}$. If an agent declares to be of type $g$ and hence trades in the market for $g$, i.e., if he chooses $z_{g} \neq 0$, then he cannot trade in the market for $b$ and he must choose $z_{b}=0$. Moreover, his net trades in the market for $g$ have to be incentive compatible with respect to the net trades made in the market by agents who claim to be of type $b$, taken as exogenously given; we will denote such trades by $\overline{\mathbf{z}}_{b} \equiv\left(0, \bar{z}_{b}\right)$. Type $b$ agents must then prefer $\bar{z}_{b}$ at least weakly to $z_{g} \cdot{ }^{7}$ Symmetric restrictions hold if the agent chooses instead to trade in the market for the $b$ types, i.e., $z_{b} \neq 0$ : type $g$ agents must prefer $\bar{z}_{g}$ to $z_{b}$, where $\overline{\mathbf{z}}_{g} \equiv\left(\bar{z}_{g}, 0\right)$.

The set of admissible net trades for each agent is then defined as follows:

$$
Z\left(\overline{\mathbf{z}}_{g}, \overline{\mathbf{z}}_{b}\right)=\left\{\begin{array}{c}
\mathbf{z}+(\omega, \omega) \in \mathbb{R}_{+}^{4}: \\
\forall i \in\{g, b\}, \quad z_{i} \neq 0 \Longrightarrow z_{j}=0 \text { for } j \neq i \text { and } \\
\sum_{s \in S} \pi_{s}^{j} u\left(\omega_{s}+\bar{z}_{j, s}\right) \geqslant \sum_{s \in S} \pi_{s}^{j} u\left(\omega_{s}+z_{i, s}\right)
\end{array}\right\}
$$

It depends on the level of trades made in the market $\overline{\mathbf{z}}_{g}, \overline{\mathbf{z}}_{b}$ via the incentive compatibility constraints imposed in the specification of this set; thereby the externality.

The choice problem of an agent of type $i \in\{g, b\}$ has then the following form:

$$
\max _{\mathbf{z} \in Z\left(\overline{\mathbf{z}}_{g}, \overline{\mathbf{z}}_{b}\right)} \sum_{s \in S} \pi_{s}^{i} u\left(\omega_{s}+\sum_{j \in\{g, b\}} z_{j, s}\right)
$$

\footnotetext{
${ }^{7}$ It is not explicitly required that type $g$ agents prefer $z_{g}$ to $\bar{z}_{b}$, as in the first of the two incentive constraints appearing in the definition of incentive constrained allocations, (2). Such constraint would in fact be redundant. Each agent trading in the market for $g$ will always choose his most preferred allocation. Therefore, he will choose an allocation that he prefers to $\bar{z}_{b}$ if such an allocation is available. But at equilibrium this will always be the case since type $g$ 's incentive constraint (2) is imposed to the problem of agents trading in the market for $b$ and at equilibrium we require $\bar{z}_{b}$ to be the actual choice made by agents trading in market $b$.
} 
s.t.

$$
\mathbf{q} \cdot \mathbf{z} \leq 0
$$

In addition to consumers there are firms who supply insurance contracts, defined by purchases and sales of claims contingent on the realization of the individual uncertainty and the agents' declared type. Moreover, firms can construct aggregates - or 'pools' - of such contracts and transform them into riskless claims by the Law of Large Numbers. Let $\mathbf{y} \equiv\left\{y_{g, H}, y_{g, L}, y_{b, H}, y_{b, L}\right\}$ denote the vector describing the supply of net trades of contingent commodities, on a per capita basis. Firms are then characterized by the following constant returns to scale technology:

$$
Y=\left\{\mathbf{y} \in \mathbb{R}^{4}: \sum_{i \in\{g, b\}} \sum_{s \in S} \pi_{s}^{i} y_{i, s} \leq 0\right\} .
$$

The technology requires that firms offer individual contracts which are self-financing in the aggregate.

The firms' problem consists in the choice of a vector $y$ lying in the set $Y$, so as to maximize profits:

$$
\max _{\mathbf{y} \in Y} \mathbf{q} \cdot \mathbf{y}
$$$$
\left(P^{E P T, f}\right)
$$

We restrict our attention here, and in what follows, to symmetric equilibria, where all agents of the same type make the same choice.

Definition 2 An EPT equilibrium is given by a collection of net trades for each type of consumer, $\left(\mathbf{z}^{g}, \mathbf{z}^{b}\right)$, a production vector $\mathbf{y}$, a price vector $\mathbf{q}$, and a pair $\left(\overline{\mathbf{z}}_{g}, \overline{\mathbf{z}}_{b}\right)$ such that:

(i) for each $i \in\{g, b\}, \mathbf{z}^{i}$ solves the optimization problem $\left(P^{E P T, i}\right)$ of consumers of type $i$, given $\left(\mathbf{q}, \overline{\mathbf{z}}_{g}, \overline{\mathbf{z}}_{b}\right)$;

(ii) y solves the firms' profit maximization problem $\left(P^{E P T, f}\right)$, given $\mathbf{q}$;

(iii) markets clear:

$$
\sum_{i} \xi^{i} \mathbf{z}^{i} \leq \mathbf{y}
$$

(iv) the level of trades in each market, taken as given by agents, is consistent with the agents' actual choice:

$$
\begin{aligned}
& \overline{\mathbf{z}}_{g}=\mathbf{z}^{g} \\
& \overline{\mathbf{z}}_{b}=\mathbf{z}^{b}
\end{aligned}
$$

Note that condition (iv) requires that at equilibrium each agent chooses to declare his true type: agents of type $g$ choose to trade in the market designated for $g$ while agents of type $b$ prefer to trade in the market designated for $b$. 
The formulation of the agents' set of admissible trades in $\left(P^{E P T, i}\right)$, together with the consistency condition (iv), ensures that the equilibrium allocation $\left(z_{g}^{g}, z_{b}^{b}\right)$ is mutually incentive compatible, that is, it satisfies (2-3).

The presence of incentive compatibility as a restriction on consumers' admissible trades can be equivalently interpreted, rather than literally as consumers 'self-imposing' such constraints, as a restriction on the set of contracts firms can offer to consumers. ${ }^{8}$ The firms' choice of $\mathbf{y}$ can in fact be viewed as the choice of the contract to offer the agents, as insurance firms do in Rothschild and Stiglitz (1976), except that in our analysis firms are price-takers. Even though the set $Y$ of contracts that are admissible for the firms is quite large, only incentive compatible contracts will be offered at equilibrium: supply has in fact to equal demand, and agents' demand is subject to the incentive compatibility constraints. Hence the set $Y$ of admissible contracts for the firms could have been restricted, without affecting the results, by imposing the incentive compatibility constraints as in (4). In this formulation a firm could only offer a contract in the market designated for the type $g$ agents if type $b$ agents preferred $\bar{z}_{b}$ to the net trades prescribed by the contract, and similarly for contracts to be offered in the market for $b$.

We are able to completely characterize the EPT equilibria of the economy under consideration. First of all, it is easy to verify that the specification of the set of admissible trades in (4) ensures that each agent will choose to trade in the market designated for his own type. Moreover, the constant returns to scale property of the firm's technology, which characterizes the set $Y$ of technologically feasible contracts firms can offer, implies that a solution of the firms' maximization problem $P^{E P T, f}$ requires prices $\mathbf{q}$ to be fair:

Lemma 1 At an EPT equilibrium, prices of contingent commodities have to be "fair":

$$
q_{i, s}=\pi_{s}^{i}, \quad i \in\{g, b\}, s \in S
$$

If in fact prices were not fair, e.g. $\pi_{L}^{b}>q_{b, L}, \pi_{H}^{b} \leq q_{b, H}$, firms could achieve unboundedly large positive profits by selling commodity $(b, H)$ and buying $(b, L)$.

At an EPT equilibrium, therefore, agents of type $b$ face fair prices and, we can show, they face no binding incentive constraint. They will then fully insure and choose the net trades corresponding to $b$ 's component of the separating allocation, $z^{b, S}=x^{b, S}-\omega$.

The set of budget feasible and incentive compatible consumption levels of type $g$ agents at the equilibrium prices is illustrated in Figure 1. It corresponds to the shaded area lying below the lower contour of the indifference curve $U^{b}$ passing through $x^{b, S}$ and the fair odds line for type $g$ which by Lemma 1 is the budget constraint in the market for $g$. The preferred point by agents of type $g$ in this set, $x^{g, S}$, is the consumption level induced by type $g$ 's net trades at the separating allocation. We conclude that the only EPT equilibrium of the economy is Rothschild and Stiglitz separating allocation.

\footnotetext{
${ }^{8}$ See also Jerez (2003) on this point.
} 
Theorem 1 Under Assumption 1, a unique EPT equilibrium allocation always exists and it coincides with Rothschild-Stiglitz separating allocation.

Thus, Rothschild and Stiglitz's pooling allocation is never an EPT equilibrium. To understand why, it is important to note at the outset that this allocation is incentive compatible and hence it is included in the commodity space. Nonetheless no vector of prices supports the pooling allocation as an EPT equilibrium. As shown in Lemma 1, in equilibrium prices have to be fair. At fair prices, though, the pooling allocation is not budget feasible for the type $b$ agents and hence it cannot be an equilibrium. This is just a consequence of the fact that the pooling allocation requires cross-subsidization from types $g$ to types $b$ and cross-subsidization requires prices not to be fair. ${ }^{9}$

We have shown that the separating allocation is always an EPT equilibrium. For the same economy Rothschild and Stiglitz (1976) find instead robust instances where the separating allocation is not an equilibrium (and no other allocation is). When all agents prefer the pooling allocation to the separating one, their argument goes, the latter is not an equilibrium because the introduction of a pooling contract constitutes a profitable deviation, since all agents will acquire it. To understand why this argument does not apply in our context, we should point out that in a Walrasian equilibrium all technologically feasible contracts $y \in Y$ are simultaneously available for trade in a competitive market. This includes the pooling, the separating, as well as the contracts which agents of type $g$ prefer to the pooling. It is indeed the availability of contracts which "skim" agents of type $g$ from the pooling which implies that the pooling is never a profitable deviation to the separating at a Walrasian equilibrium. ${ }^{10}$

\subsubsection{Welfare Properties of EPT Equilibria}

As we noticed earlier, when the fraction $\xi^{b}$ of type $b$ agents is sufficiently small the separating allocation is not incentive efficient. The characterization of EPT equilibria obtained in Theorem 1 therefore reveals that the first welfare theorem does not hold, that EPT equilibria may not be incentive efficient. This should not come as a surprise: our formulation of Walrasian equilibria in adverse selection economies, EPT, clearly identifies an externality, not internalized by the structure of markets considered, which may preclude the incentive efficiency of equilibrium allocations.

\footnotetext{
${ }^{9}$ The pooling allocation would be budget feasible for both types if $q_{g}=q_{b}$. But at these prices, as argued for Lemma 1, firms could achieve unboundedly large positive profits by selling commodity $(g, L)$ and buying $(b, L)$, i.e., by selling only insurance to the $g$ types. In other words, firms could make positive profits by 'breaking' the pooling and introducing some separation, as in the argument used by Rothschild and Stiglitz (1976) to explain why the pooling allocation is not supported as an equilibrium.

${ }^{10}$ This is not unrelated to Wilson (1977)'s and Riley (1979)'s critique of the strategic notion of equilibrium of Rothschild and Stiglitz (1976); see Bisin and Gottardi (2005) for an extended discussion of this point.
} 
It is useful however to examine more closely what is the precise source of the inefficiency. As shown by Lemma 1, at an EPT equilibrium the prices of contracts traded by each type are always fair. Thus at equilibrium there is never cross-subsidization across types. We show next that such lack of cross-subsidization is clearly responsible for the possible inefficiency of EPT equilibria and moreover it is in fact the only source of inefficiency. EPT equilibrium allocations are efficient within the restricted subset of allocations which are incentive efficient and satisfy an additional condition requiring that there is no cross-subsidization across types. ${ }^{11}$ Thus the following third best version of the first welfare theorem holds:

Proposition 1 Under Assumption 1, all EPT equilibrium allocations are efficient within the restricted set of feasible allocations which are incentive compatible and, in addition, satisfy the condition

$$
\sum_{s \in S} \pi_{s}^{i}\left(z_{s}^{i}\right) \leq 0, \quad i \in\{g, b\}
$$

On the other hand, the second welfare theorem holds for the present structure of markets: any incentive efficient consumption allocation can be decentralized as an EPT equilibrium with transfers. Let $\left(t_{H}, t_{L}\right) \in \mathbb{R}^{2}$ denote the vector of state contingent transfers to the agents. Note that transfers are same for both types since types are private information. Thus, the budget constraint of an agent who chooses to trade in the market for $i$, in the presence of the transfers $\left(t_{H}, t_{L}\right)$, is:

$$
\sum_{s \in S} q_{i, s}\left(z_{i, s}-t_{s}\right) \leq 0
$$

for $i \in\{g, b\}$. Finally, we say that a vector of transfers $\left(t_{H}, t_{L}\right)$ is feasible if

$$
\sum_{s \in S}\left[\xi^{g} \pi_{s}^{g} t_{s}+\xi^{b} \pi_{s}^{b} t_{s}\right] \leq 0
$$

Proposition 2 Let $\left(z^{g}, z^{b}\right)$ be an arbitrary incentive efficient allocation. Under Assumption 1 there exists a set of feasible transfers $\left(t_{H}, t_{L}\right) \in \mathbb{R}^{2}$ such that $\left(z^{g}, z^{b}\right)$ is the allocation obtained at the EPT equilibrium of the economy under consideration when each agent receives a transfer $\left(t_{H}, t_{L}\right)$, that is, when each agent's budget constraint is as in (8).

Figure 3 illustrates this result. For the given initial endowment $\omega$, the EPT equilibrium is the corresponding separating allocation $\left(z^{i, S}\right)_{i=g, b}$. Consider now the class of incentive efficient allocations characterized by full insurance of type $b$ agents and partial

\footnotetext{
${ }^{11}$ See Gale (1996) for a similar result for competitive equilibria of adverse selection economies with fully nonlinear price schedules.
} 
insurance of type $g$. They have the property that the consumption level of type $g$ satisfies the incentive constraint of type $b$ with equality, i.e., the consumption level of type $g$ lies on type $b$ 's indifference curve $U^{b}$. Take an arbitrary incentive efficient allocation $\left(z^{i}\right)_{i=g, b}$ in this class. Transfers $t=\left(t_{H}, t_{L}\right)$ can be constructed as in the Figure so that the EPT equilibrium (the separating allocation) associated to the endowment $\omega+t$ is in fact $\left(z^{i}\right)_{i=g, b}$. The formal proof is contained in the Appendix.

\subsection{ALPT Equilibria}

In the definition of EPT equilibria the set of admissible trades of each agent is restricted by incentive compatibility constraints which relate the level of net trades an agent can make in a market to the net trades made in the other market. This fact generates, as we noticed, an externality in consumption. To decentralize incentive efficient allocations in the adverse selection economies under consideration it is then necessary to introduce markets where agents can trade the 'commodity' which generates the externality. This is in accord with the approach proposed by Arrow (1969) and Lindahl (1919) for general economies with externalities and public goods, approach which is adopted in the design of markets for trading pollution rights (see Ledyard and Szakaly (1994)). We will refer then to the competitive equilibrium notion we obtain as Arrow-Lindahl-Prescott-Townsend (ALPT) equilibrium.

The design of a structure of markets for consumption rights which allows to decentralize incentive efficient allocations as Walrasian equilibria contains three main components: a definition of the agents' choice set which includes holdings of consumption rights, an enforcement mechanism which specifies exactly which "rights" holding consumption rights provides the agent with, and a specification of the agents' endowments of consumption rights as well as of the technology to produce them. We discuss these three components of the decentralization mechanism we design in the following, first informally and then more formally.

Consider an agent, say of type $g$. He has first of all to choose in which market to trade, either the market designated for type $g$ agents or the market for types $b$. The set of admissible net trades he will face in each market will be such as to induce him to trade in the market designated for his own type, type $g$. In this market he will trade contingent claims as well as consumption rights. To be able to realize any desired level of consumption by trading contingent claims in the market for $g$ types, the agent is required in fact to hold an appropriate amount of consumption rights, or, more precisely, of consumption rights for market $g$. This is the enforcement mechanism component of the market design. It provides a link between consumption and holdings of consumption rights with the objective of making the agent internalize the effect of his consumption on the incentive compatibility constraints of the other type: the higher the level of consumption by agents of type $g$, the tighter is the incentive constraint which has to be satisfied to prevent agents of type $b$ to pretend to be of type $g$, and hence the higher the 
amount of consumption rights for market $g$ a type $g$ agent needs to hold. ${ }^{12}$ Only when the price of consumption rights for market $g$ is zero will the agent be free to choose his trades of contingent claims in this market. In this case the enforcement mechanism does not constrain his choice.

Finally, the supply of consumption rights needs to be specified. Consider the rights for market $g$ (the supply of rights for market $b$ is symmetric). Both agents' types are assumed to be initially endowed with a certain quantity of rights for market $g$. In addition, the agents who choose to trade in the market designated for $b$ produce an additional amount of consumption rights for market $g$ directly proportional to their net trades of contingent claims. A higher level of net trades in market $b$ in fact relaxes the type $b$ 's incentive constraint and hence makes the participation in the market for agents of type $g$ easier. $^{13}$

We turn now to a formal description of the market design. Let $\mathbf{z} \equiv\left\{z_{g}, z_{b}\right\} \in \mathbb{R}^{4}$ be, as before, the vector of net trades of contingent claims, where $z_{i} \equiv\left\{z_{i, H}, z_{i, L}\right\}$ denotes the trades of an agent in the market designated for type $i \in\{g, b\}$. An agent who chooses net trades $z_{g} \neq 0$ in the market for $g$, effectively declaring to be of type $g$, cannot trade in the market designated for type $b$ agents and must therefore choose $z_{b}=0$.

To be able to trade $z_{g}$ units in the contingent claims market for $g$ and hence to consume $x_{g}=\omega+z_{g}$ units, the agent must hold an amount $\chi(g) \equiv\left\{\chi_{H}(g), \chi_{L}(g)\right\} \in \mathbb{R}_{+}^{2}$ of consumption rights for market $g$ which satisfies: ${ }^{14}$

$$
\sum_{s \in S} \pi_{s}^{b} u\left(\chi_{s}(g)\right) \geqslant \sum_{s \in S} \pi_{s}^{b} u\left(\omega_{s}+z_{g, s}\right)
$$

This specification of the enforced link between the contingent trades in the market for $g$ and the holdings of consumption rights for market $g$ guarantees that type $b$ 's incentive constraint is satisfied for the amount of rights held by the agent. Therefore, type $b^{\prime} s$ incentive constraint is internalized by agents trading in the market designated for type $g$ agents. Symmetrically, agents trading in the market for $b$ must hold an amount $\left(\chi_{H}(g), \chi_{L}(g)\right)$ of consumption rights so that type $g$ 's incentive constraint is satisfied.

The total initial endowment of consumption rights for market $g$ is $\omega \xi^{g}$. A fraction $(1-\alpha)$ of this endowment is equally distributed among the agents trading in the market for $g$, and the remaining fraction $\alpha$ is distributed to the agents trading in the market for

\footnotetext{
${ }^{12}$ The enforcement mechanism might be designed to operate on net trades rather than on consumption, to allow agents to consume their own endowment without holding any rights. We avoid making this distinction to keep simpler the presentation and the interpretation of the market mechanism.

${ }^{13}$ Arrow-Lindahl equilibrium concepts are sometimes criticized on the basis of the fact that the price taking assumptions is inconsistent with individualized prices (as markets are too 'thin'); see for instance Chari-Jones (2000). But in the economy considered here there is a continuum of agents of each type, hence the presence of markets for consumption rights for each type is still consistent with price taking behavior.

${ }^{14}$ Note that consumption rights for market $g$ are thus denominated in units of type $b$ 's consumption.
} 
$b$. Each agent trading in the market for $g$ receives therefore $(1-\alpha) \omega$ units of endowment of rights for consumption in market $g$, while $\left(\xi^{g} / \xi^{b}\right) \alpha \omega$ units of the same rights go to each agent choosing to trade in the market for $b$. The distribution of consumption rights for market $b$ is symmetric. Therefore, each agent who trades in the market for $g$ also has an endowment of $\left(\xi^{b} / \xi^{g}\right) \alpha \omega$ units of consumption rights for market $b .{ }^{15}$ The constant $\alpha$ conveniently parameterizes the distribution of the initial endowment of consumption rights across agents. The higher is $\alpha$, the lower is the initial endowment an agent has of consumption rights for the market he chooses, and hence the higher will be the amount of consumption rights an agent has to buy to be able to satisfy the constraints required to consume and trade in this market (i.e., the greater the payment needed to internalize the externality). We restrict $\alpha$ to be strictly positive: $\alpha \in(0,1]{ }^{16}$.

The outstanding amount of consumption rights is not limited to the total initial endowment distributed across the agents. Any trade of contingent claims to the consumption good in one market, in fact, produces consumption rights for the other market. More specifically, an agent choosing an amount $z_{g}$ of net trades in the market for $g$, for instance, produces an additional amount $\left(\xi^{b} / \xi^{g}\right) z^{g}$ of consumption rights for market $b$ that he can trade in the market. Let $\zeta(i) \equiv\left\{\zeta_{H}(i), \zeta_{L}(i)\right\} \in \mathbb{R}^{2}$ denote the net trades of consumption rights for market $i \in\{g, b\}$. An agent who chooses to trade in the market for $g$ holds then a total amount $\chi(g)$ of rights for consumption in the market for $g$ equal to $(1-\alpha) \omega+\zeta(g)$, while the total amount of consumption rights for market $b$ held by this agent equals $\left(\xi^{b} / \xi^{g}\right)\left(\alpha \omega+z_{g}\right)+\zeta(b)$. Since an agent has no benefit from holding consumption rights for a market other than the one where he chooses to trade, the net sales of consumption rights for market $b$ by an agent trading in the market for $g$ will typically equal the sum of the entire amount the agent is endowed and the amount he produced. (Free disposal guarantees that the equilibrium prices of consumption rights are non-negative.)

The presence of different markets designated for each type requires, as already noted, that the set of admissible trades is restricted so as to ensure that agents self-select in the market for their own private type. The imposition of incentive constraints as (9) ensures, as we shall see, that at equilibrium type $b$ agents prefer to trade in the market for $b$ rather than choosing the same trades as the agents who selected to trade in the market for $g$. This however is not enough to guarantee that they also do not prefer other trades available in the market for $g$. To rule out such possibility an additional constraint needs to be imposed. ${ }^{17}$ More specifically, we require that an agent cannot

\footnotetext{
${ }^{15}$ Note that in our formulation the endowment of consumption rights of each agent depends on his choice of the market, i.e. on his implicit declaration of his type.

${ }^{16}$ This is needed to ensure that agents can find some trades in the interior of their budget set at all prices and hence to ensure the existence of an equilibrium.

${ }^{17}$ Such constraint is not needed, as we saw, in the case of EPT. On the other hand in ALPT, where the incentive constraint faced by an agent in a market is required to hold with respect to the amount
} 
make trades in the market for $g$ that only a type $b$ agent would choose in that market, as these trades would clearly signal that the agent has untruthfully declared his type to be $g$. We exclude then as non admissible all those trades that only an agent of type $b$ would prefer to the trades that are made in this market, $\bar{z}_{g}$. This is condition (iii) in (10) below. As we will see, this guarantees that at equilibrium agents always declare their true type.

Summarizing, the set of admissible trades of every agent can be written as follows:

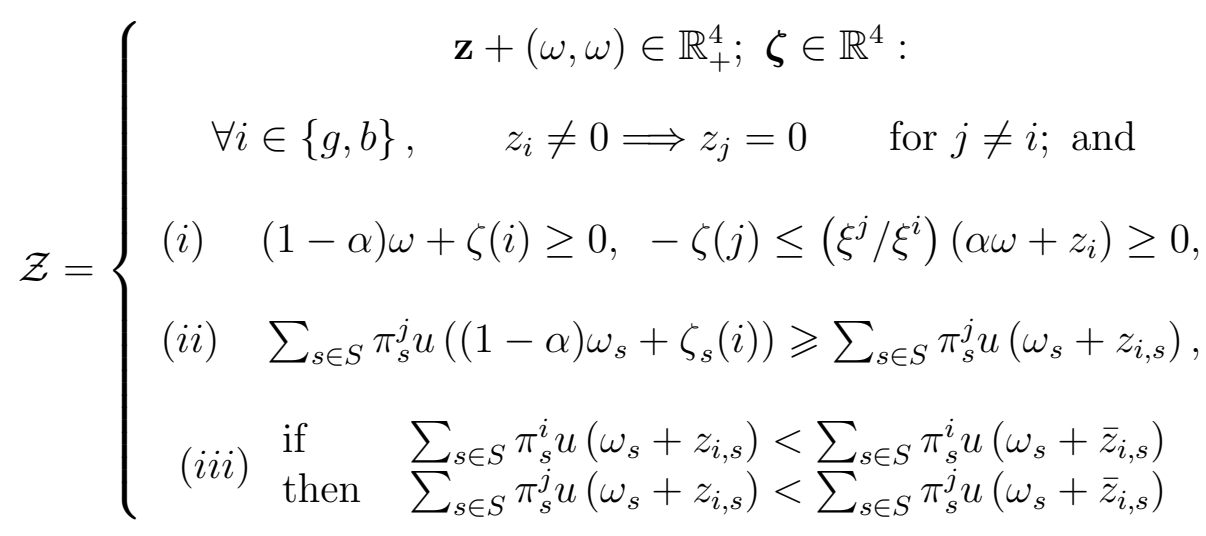

Condition (i) requires the non-negativity of the amount held of consumption rights, both for the market which is chosen as well as for the other market, while (ii) and (iii) are the incentive compatibility constraints restricting admissible trades. Condition (ii) requires each agent choosing to trade in the market for type $i$ to internalize the incentive constraint of type $j$ agents by means of his holdings of consumption rights for market $i$; (iii) together with (ii) guarantees, as we argued, that agents declaring to be of type $i$, and hence trading in the market designated for $i$, are in fact type $i$ agents.

As we noted, in EPT the presence of the incentive compatibility constraints in the specification of the set of admissible trades generates an externality. On the other hand in ALPT, where markets for consumption rights are introduced, no externality is induced by the presence of those constraints, as in condition (ii). At the same time, condition (iii) in $\mathcal{Z}$, where $\bar{z}_{i}$ appears, might seem to introduce once again an externality in the specification of the trading set and hence in the equilibrium notion. However, this is not the case (and this is why, somewhat abusing notation, we have not indexed the set of admissible net trades $\mathcal{Z}$ by $\bar{z}$ ). Condition (iii) in fact guarantees that agents self-select in the market designated for their own type, but does not affect the equilibrium allocation and prices in any other way: the condition rules in fact as non admissible in market $i$ the trades that only type $j$ but not type $i$ would make in this market. Formally, we show (see Lemma A.1 in the proof of Theorem 2 in Bisin and Gottardi (2005)) that

of consumption rights chosen by the same agent rather than to the trades made by agents in the other market, the set of admissible trades is larger and self-selection might not be induced in the absence of this constraint. Rustichini and Siconolfi (2002) do not impose this constraint and find that equilibria may not exist. 
the set of equilibria of the economy under consideration, where the choice of any agent is restricted to lie in $\mathcal{Z}$, coincides with the set of equilibria of an artificial economy in which the agents' choice is only restricted by conditions (i) and (ii) of the definition of $\mathcal{Z}$, but agents of type $i$ are required to trade in the market designated for type $i{ }^{18}$ As a consequence, even though formally the set $\mathcal{Z}$ of feasible trades of every agent still depends on the level of trades made in the market, we can argue that in this case the externality does not matter, ${ }^{19}$ as the market for consumption rights allows to properly internalize it.

The vector of prices at which consumption rights can be traded is $\mathbf{p} \equiv\left\{p_{H}(g), p_{L}(g)\right.$, $\left.p_{H}(b), p_{L}(b)\right\} \in \mathbb{R}_{+}^{4}$, while the vector of prices of state contingent commodities is again denoted as $\mathbf{q} \equiv\left\{q_{g, H}, q_{g, L}, q_{b, H}, q_{b, L}\right\} \in \mathbb{R}_{+}^{4}$. The choice problem of an agent of type $i \in\{g, b\}$ has now the following form:

$$
\max _{(\mathbf{z}, \zeta) \in \mathcal{Z}} \sum_{s \in S} \pi_{s}^{i} u\left(\omega_{s}+\sum_{j \in\{g, b\}} z_{j, s}\right)
$$

subject to

$$
\mathbf{q} \cdot \mathbf{z}+\mathbf{p} \cdot \boldsymbol{\zeta} \leq 0
$$

Firms are characterized by the same technology $Y$ as in EPT and their choice problem is also the same:

$$
\max _{\mathbf{y} \in Y} \mathbf{q} \cdot \mathbf{y} \quad\left(P^{A L P T, f}\right)
$$

We then have:

Definition 3 An ALPT equilibrium is a collection of net trades of contingent commodities and consumption rights for each type of consumer $\left(\mathbf{z}^{i}, \boldsymbol{\zeta}^{i}\right)_{i \in\{g, b\}}$, a production vector $\mathbf{y}$, a price vector $(\mathbf{p}, \mathbf{q})$ and a pair $\left(\bar{z}_{g}, \bar{z}_{b}\right)$ such that:

(i) for each $i \in\{g, b\},\left(\mathbf{z}^{i}, \boldsymbol{\zeta}^{i}\right)$ is a solution of the optimization problem $\left(P^{A L P T, i}\right)$ of type $i$ consumers, given $(\mathbf{p}, \mathbf{q})$ and $\bar{z}_{j}, j \in\{g, b\}$

(ii) y solves the firms' profit maximization problem $\left(P^{A L P T, f}\right)$, given $\mathbf{q}$;

\footnotetext{
${ }^{18}$ In this sense we can say that condition (iii) does not bind locally at equilibrium allocations. This is not to say that it is redundant. We have in fact already noted (see footnote 17) that it is not. To understand this we should observe that the maximization problem of each agent in our economy is not convex, and includes in particular a binary choice regarding which market to trade in.

${ }^{19}$ This can be done formally. An alternative equivalent specification of condition (iii), where no reference to $\bar{z}_{i}$ is made, is in fact possible, but at the cost of some non transparent notation and hence we opted here for the specification in (10).
} 
(iii) markets clear, both for contingent commodities:

$$
\sum_{i} \xi^{i} \mathbf{z}^{i} \leq \mathbf{y}
$$

and for consumption rights:

$$
\sum_{i} \xi^{i} \zeta^{i} \leq 0
$$

(iv) the level of trades in each market, taken as given by agents, is consistent with the agents' actual choice:

$$
\bar{z}_{j}=z_{j}^{j}, j \in\{g, b\}
$$

As the analogous condition in EPT, the consistency condition (iv) requires that at equilibrium agents choose to declare their type truthfully. Also, the specification of the set of admissible trades $\mathcal{Z}$, together with the consistency and the market clearing conditions (iii) and (iv), implies that the level of consumption of type $b$ agents, $\omega+z_{b}$, equals the amount of consumption rights for market $g$ held by type $g,(1-\alpha) \omega+\zeta(g)$. As a consequence, again, the equilibrium consumption allocation, $\left(z_{b}^{b}, z_{g}^{g}\right)$ is mutually incentive compatible.

We can show ${ }^{20}$ that, for the economy under consideration, an ALPT equilibrium always exists: ${ }^{21}$

Theorem 2 Under Assumption 1, an ALPT equilibrium always exists.

We derive next a characterization of ALPT equilibria. This allows us to better understand how the markets for consumption rights we designed work and will also be of use in our analysis of the welfare properties of ALPT.

First of all, in the proof of Theorem 2 in Bisin and Gottardi (2005) we show that there is always an ALPT equilibrium where prices are as follows:

$$
q_{i, s}=\pi_{s}^{i}, s \in S, i \in\{g, b\}
$$

\footnotetext{
${ }^{20}$ Standard arguments cannot be directly applied here. We refer to Bisin and Gottardi (2005) for a discussion of the methods used to establish existence, and for the proof of the result.

${ }^{21}$ In the working paper version of Prescott and Townsend (1984) the authors briefly discuss a notion of competitive equilibrium for adverse selection economies which is related to ALPT. In their formulation, however, each type of agent chooses directly the consumption level of the other type rather than the amount of consumption rights. In our context this is equivalent to the requirement that, e.g., the price agents face for consumption rights for market $g, p(g)$, is the same as the price that agents face for consumption claims in the market for type $b, q_{b}$. At these prices, the choices made by the two types of agents in the two markets will typically not be consistent; that is, in our notation, $\zeta(g)+(1-\alpha) \omega \neq z_{b}+\omega$. As a consequence, as Prescott and Townsend notice, an equilibrium will generally fail to exist.
} 


$$
p_{s}(g)=\beta \pi_{s}^{b}, \quad p_{s}(b)=0, s \in S
$$

for some $\beta \in\left(0, \xi^{b} / \xi^{g}\right)$. The form of these equilibrium prices clearly illustrates how incentive efficient allocations are sustained as ALPT equilibria. The prices $\mathbf{q}$ at which agents can trade the contingent claims for the consumption good are fair, as in EPT. But then the type $g$ agents have to pay a positive price to acquire the consumption rights for market $g$ needed to satisfy the required incentive compatibility constraint. Type $b$ agents, on the other hand, receive a positive revenue from the sale of these consumption rights. Furthermore, the consumption rights for market $b$ trade at a zero price. As a consequence, agents of type $b$ do not have to pay any cost to ensure the incentive compatibility of their consumption, and agents of type $g$ receive nothing from the sale of these rights. At the equilibrium allocation obtained at the above prices, type $b$ 's incentive constraint (3) is binding, the consumption of the $g$ agents exerts then a negative externality on type $b$ agents, and the positive equilibrium price of consumption rights for market $g$ induces a subsidy from agents of type $g$ to agents of type $b$. Consumption rights for market $b$ trade at a zero price, on the other hand, because at equilibrium type $g$ 's incentive constraint (2) is not binding and hence the consumption of agents of type $b$ generates no externality on agents of type $g$.

Figure 4 below illustrates such an ALPT equilibrium. In particular, the shaded area represents the set of admissible and budget feasible trades of contingent claims in the market designated for type $g$, at an ALPT equilibrium. It is typically larger than the corresponding set in EPT, depicted by the shaded area in Figure 1. The solid curve in Figure 4, representing the boundary of the set of admissible and budget feasible trades of contingent claims in the market for $g$, is obtained using the characterization of the equilibrium prices in (11-12). ${ }^{22}$ The equilibrium level of consumption for type $g$ agents, given by the point $x^{g, A}$, corresponds to their preferred bundle on this curve. The equilibrium consumption level of type $b$ agents (not in the figure) is then given by the highest full insurance point in their budget set, where their income includes the revenue from the sale of consumption rights.

Is the presence of some level of cross-subsidization an intrinsic feature of ALPT equilibria? To answer this question, we examine how the equilibrium varies with the initial distribution of consumption rights, as parameterized by $\alpha$. Let us denote by $\beta(\alpha)$ the equilibrium value of $\beta$ associated to a given level of $\alpha$ in expression (12) of equilibrium prices; analogously, let $x(\alpha)$ be the corresponding equilibrium consumption level. In the next proposition we show that, as $\alpha$ tends to 0 , the sequence of ALPT equilibrium consumption levels $\left\{x^{g}(\alpha), x^{b}(\alpha)\right\}$ converges to $\left(\underline{x}^{i} \equiv \omega+\underline{z}^{i}\right)_{i \in\{g, b\}}$, where $\left(\underline{z}^{g}, \underline{z}^{b}\right)$ is the incentive efficient allocation characterized by the minimum level of subsidization from agents of type $g$ to agents of type $b$. More formally, $\left\{\underline{z}^{g}, \underline{z}^{b}\right\}$ is obtained as a solution of the problem of maximizing the expected utility of type $g$ agents, $U^{g}\left(\omega+z^{g}\right)$, subject to the

\footnotetext{
${ }^{22}$ See the caption of the Figure for details.
} 
resource feasibility and incentive compatibility constraints, and the additional constraint that $\sum_{s} \pi_{s}^{b} z_{s}^{b} \geq 0$, i.e., that $b$ is not subsidizing $g$. It is immediate to see, given the characterization provided of incentive efficient allocations, that $\left(\underline{z}^{g}, \underline{z}^{b}\right)$ coincides with the Rothschild and Stiglitz separating allocation whenever this is incentive efficient, and is otherwise (when the constraint $\sum_{s} \pi_{s}^{b}\left(z_{s}^{b}\right) \geq 0$ is not binding) given by the incentive efficient allocation at which $b$ 's welfare is minimal. ${ }^{23}$

Proposition 3 Under Assumption 1, $\lim _{\alpha \rightarrow 0} x^{i}(\alpha)=\underline{x}^{i}$, for $i \in\{g, b\}$.

As shown in the proof of the Proposition in the Appendix, for each $\alpha>0$, the ALPT equilibrium characterized by prices of the form (11-12) exhibits a positive subsidy from the $g$ types to the $b$ types. The way in which type $b$ agents receive a subsidy is through the sale of consumption rights for market $g$. When $\alpha$ approaches 0 , the initial distribution of consumption rights is the most favorable to the type $g$ agents, as they receive in the limit the entire amount of the total initial endowment of consumption rights for market $g$; hence the sale of such rights by the $b$ agents will be the lowest, and the equilibrium will be the incentive efficient allocation $\left\{\underline{z}^{g}, \underline{z}^{b}\right\}$ where the subsidy to the $b$ agents is minimal. We show in the proof of Proposition 3 that, for the economies in which the Rothschild and Stiglitz separating allocation is incentive efficient, this allocation is decentralized as an ALPT equilibrium with $\alpha=0$, and the equilibrium prices satisfy (12) with $\beta=$ $\lim _{\alpha \rightarrow 0} \beta(\alpha)<\left(\xi^{b} / \xi^{g}\right)$. On the other hand, for the economies in which the Rothschild and Stiglitz separating allocation is not incentive efficient an ALPT equilibrium does not exist when $\alpha=0,{ }^{24}$ but the sequence of ALPT equilibria allocations converges, as $\alpha \rightarrow 0$, to $\left\{\underline{z}^{g}, \underline{z}^{b}\right\}$, the allocation with the minimum level of subsidization from agents of type $g$ to agents of type $b$, and equilibrium prices in the limit satisfy (12) with $\lim _{\alpha \rightarrow 0} \beta(\alpha)=\left(\xi^{b} / \xi^{g}\right)$.

\subsubsection{Welfare Properties of ALPT Equilibria}

First of all we show that the structure of markets for consumption rights we have designed does indeed solve the problem of decentralizing incentive efficient allocations. Proposition 4 represents (an incentive constrained version of) the First Theorem of Welfare Economics for economies with adverse selection:

Proposition 4 All ALPT equilibria are incentive efficient.

Moreover, using the characterization of ALPT equilibria with $\alpha=0$ provided by Proposition 3, it is straightforward to extend the second welfare theorem obtained for EPT equilibria, Proposition 2, to ALPT equilibria. Any incentive efficient consumption

\footnotetext{
${ }^{23}$ Note that $\left\{\underline{z}^{g}, \underline{z}^{b}\right\}$ is also the allocation induced by what is sometimes referred to as the WilsonMiyazaki pair of contracts.

${ }^{24}$ See footnote 16 .
} 
allocation can be decentralized as an ALPT equilibrium with an initial distribution of rights given by $\alpha=0$ and with transfers which are possibly dependent on the state but not the agents' type.

Proposition 5 Under Assumption 1, for any incentive efficient consumption allocation $\left(z^{g}, z^{b}\right)$ there exists a set of feasible transfers $\left(t_{H}, t_{L}\right)$, such that $\left(z^{g}, z^{b}\right)$ is an $A L P T$ equilibrium allocation when each agent receives the transfer $\left(t_{H}, t_{L}\right)$, and $\alpha=0$.

\subsubsection{The Implementation of ALPT Equilibria}

While we have shown that by appropriately designing markets for consumption rights incentive Pareto optimal allocations can be decentralized as Walrasian equilibria, such markets might appear difficult to implement in actual economies. The objective of this section is to argue that, on the contrary, markets for consumption rights can be more simply implemented when designed along the lines, e.g., of markets for pollution rights, or of markets for the access to clubs. More specifically, this is the case if the enforcement mechanism operates on insurance firms rather than consumers, linking the contracts they may offer to their holdings of appropriate amounts of trading rights. Moreover, the implementation is simplified if only offering contracts in the market for type $g$ agents, the high quality market in our set-up, requires holding of such rights and if units are re-defined so that every consumer is endowed with a single unit of the right to trade in the market for $g .{ }^{25}$

We now illustrate how such a decentralization scheme may work and give rise to the same equilibrium outcomes as the structure of markets considered in ALPT. There are again two markets, one for the agents (declaring to be) of type $b$ and one for those (declaring to be) of type $g$. If a consumer chooses to trade in the market for $b$, he can sell the right to trade in the market for $g$, at a price determined in equilibrium.Such rights are purchased by insurance firms. To be able to sell a contract in the market for $g$ a firm has in fact to satisfy an enforcement constraint, which prescribes that the contract is backed by an appropriate amount of trading rights. More precisely, the contract has to satisfy an incentive constraint requiring that only type $g$ agents prefer it to the consumption level that can be attained in the market for $b$ with the sale of the amount of trading rights backing the contract. Each firm may then offer a menu of contracts in the market for $g$, indexed by the amount of rights backing them: the larger this amount the better the contract, since the incentive compatibility constraint will be looser. No enforcement constraint, on the other hand, operates on contracts offered in the market for type $b$, the low quality market. In this market firms are free to choose the specification of the contract, i.e., the net payment to the agent in each state, so as to maximize profits.

\footnotetext{
${ }^{25}$ See Carlson et. al. (1993) and Ledyard and Szakaly (1994) for a discussion of the properties of enforcement mechanisms in the market for pollution rights which make them easily and effectively implementable.
} 
The consumers trading in each market face then a given menu of contracts among which they can choose, which at equilibrium coincides with the menu of contracts firms are willing to offer in the two markets. At a competitive equilibrium every agent chooses to trade in the market designated for his type and markets clear. In particular, the number of trading rights bought by firms operating in the market for $g$ is equal to the number of agents of type $b$ in the economy, who all sell the right to trade in the market for $g$ they are endowed with.

It is possible to show that there is always a competitive equilibrium for this economy where prices have the following properties: (i) the rights to trade in the market for $g$ have a positive price; (ii) each contract offered in the market for $b$ is priced fairly; (iii) the price of any contract offered in the market for $g$ equals the sum of the value of the contingent claims included in the contract, evaluated at the fair price $q_{g, s}=\pi_{s}^{g}, s \in S$, and the market value of the trading rights backing the contract. At such prices, the type $b$ agents choose to fully insure in the market for $b$, and use the proceeds from the sale of their right to trade in the market for $g$ to attain a level of consumption which is higher than the expected value of their endowment. Type $g$ agents choose instead a partial insurance contract in the market for $g$. This contract is backed by a smaller amount of rights, and hence cheaper than the full insurance contract. In particular, we can also show that the competitive equilibrium allocation is the same as the one obtained as the limit of ALPT equilibria, for $\alpha \rightarrow 0:^{26}$ the structure of markets described decentralizes then the allocation $\left\{\underline{z}^{g}, \underline{z}^{b}\right\}$, the incentive efficient allocation which is preferred by the type $g$ agents; that is, the Rothschild and Stiglitz separating allocation when it is incentive efficient.

With the objective of exploring some strategic foundations for our notion of ALPT equilibrium, we have also studied an extension of the definition of the core proposed by Marimon (1988) (see also Boyd-Prescott-Smith (1988)) for adverse selection economies. ${ }^{27}$ Such notion is characterized by the fact that blocking coalitions cannot tax, only subsidize agents outside the coalition, but otherwise agents of one type can separate at no cost. It is fairly immediate to see that a single allocation is in the core according to this notion, and is $\left\{\underline{z}^{g}, \underline{z}^{b}\right\}$. But suppose instead that the high quality types ( $g$ in our set-up) can form a coalition excluding the low quality types (b) only if they pay a given amount $C$, which we can interpret as the cost of acquiring the 'right' to separate from the low quality types (of course the allocation proposed by the deviating coalition must also be incentive compatible). This clearly parallels the role of the distribution of the endowment of consumption rights in ALPT. It can be shown that, by varying $C$, we can obtain as core allocations the set of ALPT equilibrium allocations corresponding to

\footnotetext{
${ }^{26}$ See Proposition 3.

${ }^{27}$ It should be pointed out though that various other notions have been proposed and an agreements has not yet been reached on what is an appropriate notion of the core for economies with adverse selection.
} 
different values of $\alpha$.

\section{Conclusions}

We have studied in this paper how Walrasian markets work in economies with adverse selection when exclusive contracts are available and whether their outcome is efficient. In particular, we have identified a form of externality as a potential problem for the operation of Walrasian markets in this set-up. We have then shown that an enlarged structure of markets, which includes markets for consumption rights, allows to internalize this externality and hence to decentralize incentive efficient allocations. All Walrasian (ALPT) equilibrium allocations are incentive efficient in this case. We have also shown that when such enlarged set of markets is not available, a Walrasian (EPT) equilibrium always exists but may fail to be incentive efficient, and inefficiency is robust.

Our results have been derived for a class of simple insurance economies with adverse selection where agents can be of two possible types, and the privately observed type of each agent only concerns the probability structure of the idiosyncratic shocks affecting the agent. Such economies provide an important benchmark for the analysis of markets and equilibria with asymmetric information, at least since the work by Rothschild and Stiglitz (1976). However, the equilibrium concepts we introduced can be extended to more general classes of economies with adverse selection. 


\section{Appendix}

We omit the proof of Theorems 1 and 2, showing the existence of EPT and of ALPT equilibria. We refer the interested reader to Bisin and Gottardi (2005).

Proof of Proposition 1. If, at a solution of the problem of maximizing a weighted average of the agents' utility subject to (2-3) and (7), both incentive compatibility constraints hold as equalities, under the assumptions made on agents' preferences (in particular, the single crossing property) we must have $z^{g}=z^{b}$. But then (7) implies that $z$ lies on, or below, the fair odds line for type $b$. Since the separating allocation is always preferred by both agents to any point on this line, this cannot be a solution.

On the other hand, if only one of the two incentive constraints is binding, say the one for type $b$ (given by (3)), then the optimal level of $z^{b}$ is simply obtained by maximizing $U^{b}\left(\omega+z^{b}\right)$ over $(7)$; thus it will always be at the full insurance point $\omega_{H}+z_{H}^{b}=\omega_{L}+z_{L}^{b}$ satisfying (7). The level of $z^{g}$ is then determined by maximizing $U^{g}\left(\omega+z^{g}\right)$ subject to (7) and (3), taking $\omega+z^{b}$ as given at the full insurance level determined before. It is immediate to see that the pair $\left(z^{g}, z^{b}\right)$ is the same as the separating allocation of Rothschild and Stiglitz. If we apply a symmetric argument when (2) is the only constraint binding, we find that no solution exists in this case (when $z^{g}$ is at the full insurance level satisfying (7), no value exists for $z^{b}$ which also satisfies (7) and (2)).

Proof of Proposition 2. Let $\left(z^{g}, z^{b}\right)$ be an arbitrary incentive efficient allocation. By Lemma 1, at an EPT equilibrium, prices of contingent commodities are necessarily 'fair'. If we consider then the budget lines $\sum_{s \in S} \pi_{s}^{b}\left(\omega_{s}+z_{b, s}^{b}\right)$ and $\sum_{s \in S} \pi_{s}^{g}\left(\omega_{s}+z_{g, s}^{g}\right)$ going through, respectively, the points $\omega+z^{b}$ and $\omega+z^{g}$, they will intersect at a single point; call it $\widetilde{x}$. Since $\sum_{s \in S} \pi_{s}^{i}\left(\omega_{s}+z_{s}^{i}\right)=\sum_{s \in S} \pi_{s}^{i} \widetilde{x}_{s}, i \in\{g, b\}$, and $\left(z^{g}, z^{b}\right)$ satisfies the resource feasibility condition (1), the allocation $(\widetilde{x}-\omega, \widetilde{x}-\omega)$ is also feasible:

$$
\sum_{s \in S}\left[\xi_{g} \pi_{s}^{g}\left(\widetilde{x}_{s}-\omega_{s}\right)+\xi_{b} \pi_{s}^{b}\left(\widetilde{x}_{s}-\omega_{s}\right)\right] \leq 0,
$$

which implies that a transfer $\left(t_{H}=\widetilde{x}_{H}-\omega_{H}, t_{L}=\widetilde{x}_{L}-\omega_{L}\right)$ to all the agents is also feasible.

We show next that $\left(z^{g}, z^{b}\right)$ is the (unique in fact) EPT equilibrium allocation of the economy when the agents receive the transfer $t=\left(t_{H}, t_{L}\right)$. Suppose not. There exists then another vector of net trades, say $\left(\hat{z}^{g}, 0\right)$ for $g$, that also lies in $Z\left[\left(z^{g}, 0\right),\left(0, z^{b}\right)\right]$, i.e. $\hat{z}^{g}$ is incentive compatible relative to $z^{b}$, and budget feasible $\left(\sum_{s} \pi_{s}^{g}\left(\hat{z}_{s}^{g}-t_{s}\right) \leq 0\right)$, and is such that $\hat{z}^{g}$ is strictly preferred to $z^{g}$ by type $g$. But then $\sum_{s \in S}\left[\xi_{g} \pi_{s}^{g}\left(\hat{z}_{s}^{g}-t_{s}\right)+\xi_{b} \pi_{s}^{b}\left(z_{s}^{b}-t_{s}\right)\right] \leq$ 0 ; thus $\left(\hat{z}^{g}, z^{b}\right)$ is also feasible, incentive compatible and Pareto dominates $\left(z^{g}, z^{b}\right)$, a contradiction.

Proof of Proposition 3. At any ALPT equilibria where prices are of the form (11-12) 
type $b$ agents face a zero price for the rights for consumption in market $b$. Hence their consumption choice is not constrained by incentive compatibility and they always choose to fully insure:

$$
z_{b, H}^{b}+\omega_{H}=z_{b, L}^{b}+\omega_{L}=\frac{\left(1-\beta\left(\xi^{g} / \xi^{b}\right)(1-\alpha)\right)\left(\sum_{s \in S} \pi_{s}^{b} \omega_{s}\right)}{1-\beta\left(\xi^{g} / \xi^{b}\right)} .
$$

The term on the right hand side is the income of a type $b$ agent, given by the value of his endowment of contingent claims, evaluated at $q_{b}=\pi^{b}$, plus the value of the amount of consumption rights for market $g$ the agents possesses, evaluated at $p(b)=\beta \pi^{b}$. The equilibrium consumption level of the type $b$ agents, as $\alpha$ varies, is then:

$$
x_{s}^{b}(\alpha)=\frac{\left(1-\left(\xi^{g} / \xi^{b}\right) \beta(\alpha)(1-\alpha)\right)\left(\sum_{s \in S} \pi_{s}^{b} \omega_{s}\right)}{1-\left(\xi^{g} / \xi^{b}\right) \beta(\alpha)}, \quad s \in S,
$$

and the subsidy received by $b, \sum_{s \in S} \pi_{s}^{b}\left(x_{s}^{b}(\alpha)-\omega_{s}\right)$, is equal to $\frac{\left(\xi^{g} / \xi^{b}\right) \alpha \beta(\alpha)}{1-\left(\xi^{g} / \xi^{b}\right) \beta(\alpha)} \sum_{s \in S} \pi_{s}^{b} \omega_{s}$.

Both sequences $x(\alpha)$ and $\beta(\alpha)$, giving the equilibrium consumption level and rights' prices for different values of $\alpha$, lie in compact sets. Thus, they admit convergent subsequences; let $\hat{x}, \hat{\beta}$ be their limit. On the basis of the above argument, If $\hat{\beta}=\lim _{\alpha \rightarrow 0} \beta(\alpha)$ is strictly less than $\left(\xi^{b} / \xi^{g}\right)$, the value of the subsidy converges to 0 as $\alpha \rightarrow 0$, so that $x^{b}(\alpha)$ converges to full insurance at fair odds, i.e. to type $b$ 's component of the consumption level at the Rothschild and Stiglitz separating allocation, $x^{b, S}=\omega+z^{b, S}$. ¿From the first welfare theorem (Proposition 4) $z^{b, S}$ must be part of an incentive efficient allocation, hence $x^{g}(\alpha)$ must converge to $x^{g, S}=\omega+z^{g, S}$ and the separating allocation $z^{g, S}, z^{b, S}$ coincides with $\left\{\underline{z}^{g}, \underline{z}^{b}\right\}$ in this case.

On the other hand, if $\hat{\beta}=\left(\xi^{b} / \xi^{g}\right)$, the problem of agents of type $g,\left(P_{A L P T}^{g}\right)$, in the limit (for $\alpha=0, \beta=\left(\xi^{b} / \xi^{g}\right)$ ), reduces to the problem of maximizing $U^{g}\left(\omega+z^{g}\right)$ (with respect to $\left.z^{g}, z^{b}\right)$ subject to the resource feasibility and incentive constraints (1-3) (since the budget constraint coincides with (1)). The solution of this problem is $\left\{\underline{z}^{g}, \underline{z}^{b}\right\}$. Note that the value of the subsidy to agents of type $b$ in this case converges to a level which is either positive or zero (but cannot be negative since it is strictly positive for all $\alpha>0$ ).

Proof of Proposition 4. The proof is quite standard. Suppose not, i.e. there exists a feasible, incentive compatible allocation $\left(\widehat{z}^{g}, \widehat{z}^{b}\right)$ which Pareto dominates the equilibrium allocation $\left(z_{g}^{g}, z_{b}^{b}\right)$. Then, note that the following constitutes an admissible choice (i.e., that lies in $\mathcal{Z})$ for agent $i \in\{g, b\}: \hat{z}_{i}^{i}=\widehat{z}^{i}, \hat{z}_{j}^{i}=0, \hat{\zeta}^{i}(i)=\alpha \omega+\hat{z}^{j}, \hat{\zeta}^{i}(j)=-\left(\xi^{j} / \xi^{i}\right)[\alpha \omega+$ $\hat{z}^{i}$ ], for $j \neq i$. Therefore, given the fact that local nonsatiation holds, as shown in the proof of Theorem 2 in Bisin and Gottardi (2005), it must be:

$$
q_{g} \cdot \widehat{z}^{g}+p(g)\left[\alpha \omega+\hat{z}^{b}\right]-p(b)\left(\xi^{b} / \xi^{g}\right)\left[\alpha \omega+\hat{z}^{g}\right] \geqslant 0
$$




$$
q_{b} \cdot \widehat{z}^{b}+p(b)\left[\alpha \omega+\hat{z}^{g}\right]-p(g)\left(\xi^{g} / \xi^{b}\right)\left[\alpha \omega+\hat{z}^{b}\right] \geqslant 0
$$

one of the two inequalities being strict. Summing then the two inequalities, multiplied respectively by $\xi^{g}$ and $\xi^{b}$, we get:

$$
\xi^{g} q_{g} \cdot \widehat{z}^{g}+\xi^{b} q_{b} \cdot \widehat{z}^{b}>0 .
$$

Since $\left(\widehat{z}^{g}, \widehat{z}^{b}\right)$ is a feasible allocation, $\left(\xi^{g} \widehat{z}^{g}, \xi^{b} \widehat{z}^{b}\right)$ lies in the firms' production possibilities' set $Y$ and, by the previous inequality, yields positive profits. This contradicts the fact that the production plan chosen by the firms at equilibrium, $\left(\xi^{g} z_{g}^{g}, \xi^{b} z_{b}^{b}\right)$, maximizes their profits at the prices $q$, since its profits equal zero.

Proof of Proposition 5. Let $\left(z^{g}, z^{b}\right)$ be any incentive efficient allocation. By Proposition 2 , there exists a set of feasible transfers $\left(t_{H}, t_{L}\right)$ such that $\left(z^{g}, z^{b}\right)$ is an EPT equilibrium allocation for the economy under consideration when each agent receives a transfer $\left(t_{H}, t_{L}\right)$. Moreover, by Theorem 1 and Proposition 2, the economy where agents' endowment equals $\omega+t$ has a unique EPT equilibrium (where the agents' consumption is given by $\left.\left(\omega+z^{g}, \omega+z^{b}\right)\right)$, coinciding with the Rothschild and Stiglitz separating allocation for the economy with endowment $\omega+t$. Since $\left(\omega+z^{g}, \omega+z^{b}\right)$ is incentive efficient, from Proposition 3 it follows that it can be decentralized as an ALPT equilibrium with $\alpha=0$ of the economy with endowments $\omega+t$. 


\section{References}

Arrow, K. (1969): 'The Organization of Economic Activity: Issues Pertinent to the Choice of Market Versus Non-Market Allocation', in Collected Papers of K. J. Arrow, vol. 2, Cambridge, Ma: Harvard University Press, 1983.

Bennardo, A. and P.A. Chiappori (2003): 'Bertrand and Walras Equilibria under Moral Hazard', Journal of Political Economy, 111(4), 785-817.

Bisin, A. and P. Gottardi (1999): 'Competitive Equilibria with Asymmetric Information', Journal of Economic Theory, 87, 1-48.

Bisin, A. and P. Gottardi (2005): Appendix to 'Efficient Competitive Equilibria with Adverse Selection', in http://www.econ.nyu.edu/user/bisina and http://venus.unive.it/ ${ }^{\text {gottardi/. }}$

Boyd, J.H., E.C. Prescott, and B.D. Smith (1988): 'Organizations in Economic Analysis', Canadian Journal of Economics, 21, 477-91.

Carlson, D., C. Forman, J. Ledyard, N. Olmstead, C. Plott, D. Porter, and A. Sholtz (1993): An Analysis and Recommendation for the Terms of the RECLAIM Trading Credit, Pacific Stock Exchange Technical Report.

Chari, V.V. and L. Jones (2000): 'A Reconsideration of the Problem of Social Cost: Free Riders and Monopolists,' Economic Theory, 16, 1-22.

Cole, H. (1989): 'Comment: General Competitive Analysis in an Economy with Private Information', International Economic Review, 30, 249-52.

Crocker, K.J. and A. Snow (1985): 'The Efficiency of Competitive Equilibria in Insurance Markets with Asymmetric Information', Journal of Public Economics, 26, 207-219.

Dubey, P., J. Geanakoplos, and M. Shubik (1995): 'Default and Efficiency in a General Equilibrium Model with Incomplete Markets', Yale University, mimeo.

Gale, D. (1992): 'A Walrasian Theory of Markets with Adverse Selection', Review of Economic Studies, 59, 229-55.

Gale, D. (1996): 'Equilibria and Pareto Optima of Markets with Adverse Selection', Economic Theory, 7, 207-36.

Hellwig, M. (1987): 'Some Recent Developments in the Theory of Competition in Markets with Adverse Selection', European Economic Review, 31, 319-325. 
Jerez, M. B. (2003): 'General Equilibrium with Asymmetric Information: A Dual Approach', Journal of Economic Theory, 112, 1-34.

Kehoe, T., D. Levine, and E.C. Prescott (2002): 'Lotteries, Sunspots, and Incentive Constraints', Journal of Economic Theory, 107, 39-69.

Kocherlakota, N. (1998): 'The Effect of Moral Hazard on Asset Prices when Financial Markets Are Complete', Journal of Monetary Economics, 41, 39-56.

Ledyard, J. and K. Szakaly (1994): 'Designing Organizations for Trading Pollution Rights,' Journal of Economic Behavior and Organization, 25, 327-355.

Lindahl E. (1919): Die Gerechtigkeit der Besteuring, Lund: Gleerup. [English translation: 'Just Taxation: A Positive Solution', in Classics in the Theory of Public Finance, edited by R. A. Musgrave and A. T. Peacock, London: Macmillan.]

Marimon, R. (1988): 'The Core of Private Information Economies', University of Minnesota, mimeo.

Maskin, E. and J. Tirole (1992): 'The Principal-Agent Relationship with an Informed Principal, II: Common Values', Econometrica, 60-1, 1-42.

Prescott, E.C. and R. Townsend (1984): 'Pareto Optima and Competitive Equilibria with Adverse Selection and Moral Hazard', Econometrica, 52, 21-45; and extended working paper version dated 1982.

Prescott, E.C. and R. Townsend (1984b): 'General Competitive Analysis in an Economy with Private Information', International Economic Review, 25, 1-20.

Riley, J. (1979): 'Informational Equilibrium', Econometrica, 47, 331-59.

Rothschild, M. and J. Stiglitz (1976): 'Equilibrium in Competitive Insurance Markets: An Essay in the Economics of Imperfect Information', Quarterly Journal of Economics, 80, 629-49.

Rustichini, A. and P. Siconolfi (2002): 'General Equilibrium in Economies with Adverse Selection', mimeo.

Wilson, C. (1977): 'A Model of Insurance Markets with Incomplete Information', Journal of Economic Theory, 16, 167-207. 


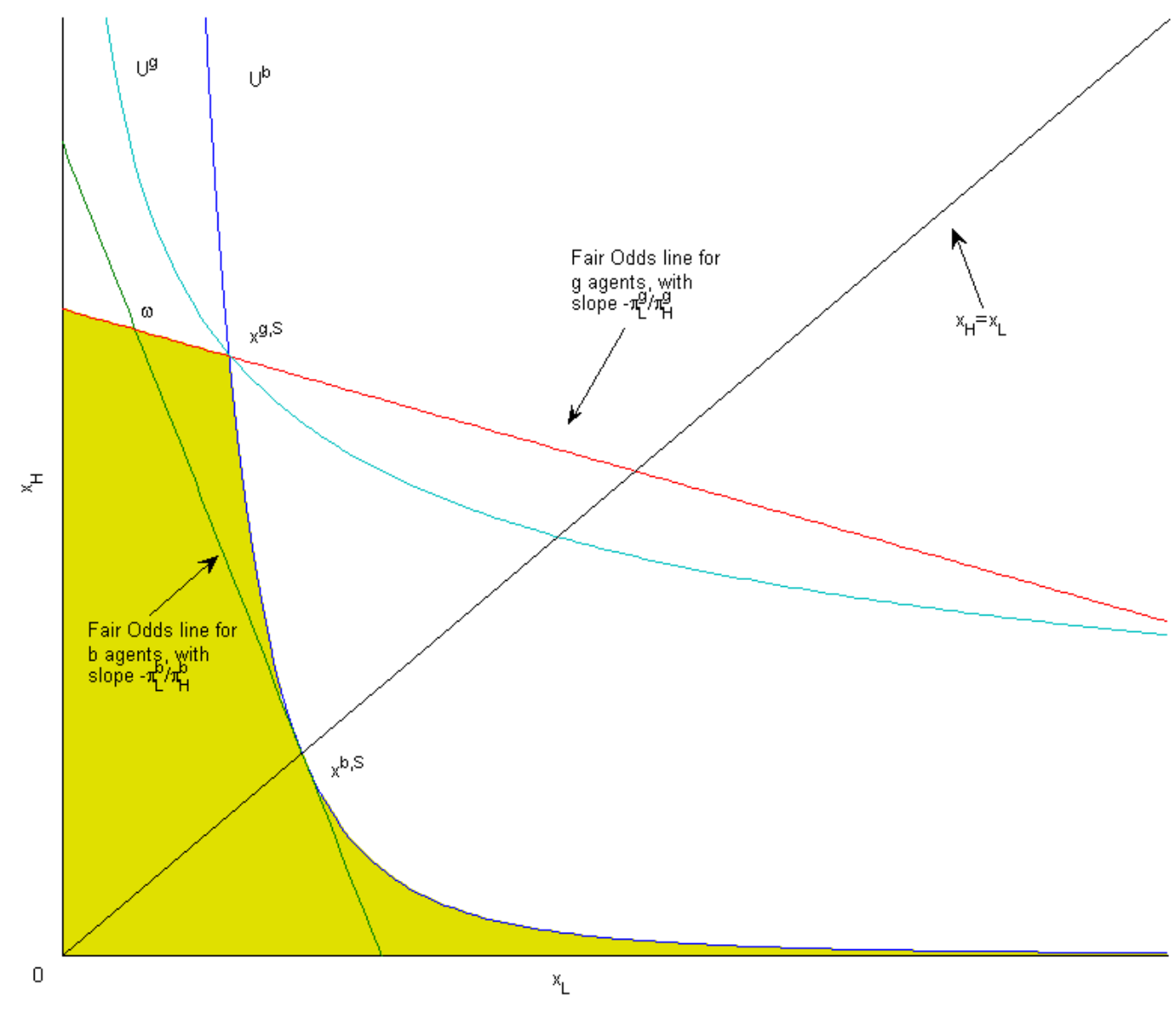

Figure 1: The Separating Allocation. $\omega$ denotes the individual endowment, $\left(x^{i, S}\right)_{i=g, b}$ the consumption level at the separating allocation, that is, $x^{i, S}=\omega+z^{i, S} ; U^{b}$ and $U^{g}$ denote the indifference curves respectively of type $b$ and $g$ at this allocation. Agents of type $b$ are fully insured at fair odds: $x_{s}^{b, S}=\sum_{s \in S}\left[\pi_{s}^{b} \omega_{s}\right]$ for each $s$. Type $g$ agents are only partially insured, again at fair odds, so as to satisfy the type $b$ incentive compatibility constraint: $x^{g, S}$ lies at the intersection of $U^{b}$ and $g$ 's fair odds line. 


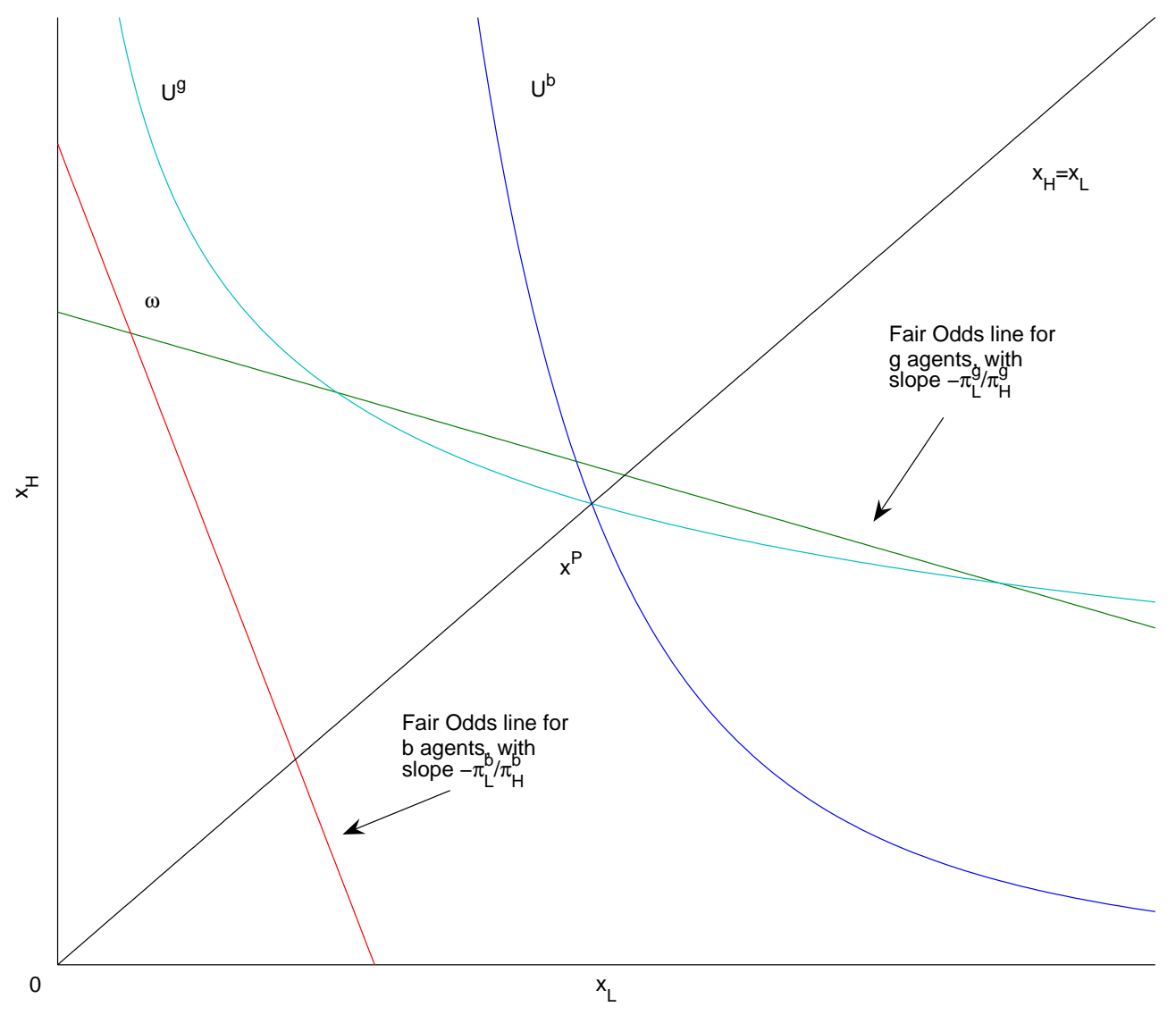

Figure 2: The Pooling Allocation. $x^{P}=\omega+z^{P}$ denotes the consumption level at the pooling allocation, $U^{b}$ and $U^{g}$ the indifference curves of types $b$ and $g$, respectively, at the pooling allocation. Both types of agents are fully insured and consume the aggregate per capita endowment: $x^{P}=\sum_{s \in S}\left[\xi^{g} \pi_{s}^{g} \omega_{s}+\xi^{b} \pi_{s}^{b} \omega_{s}\right]$. 


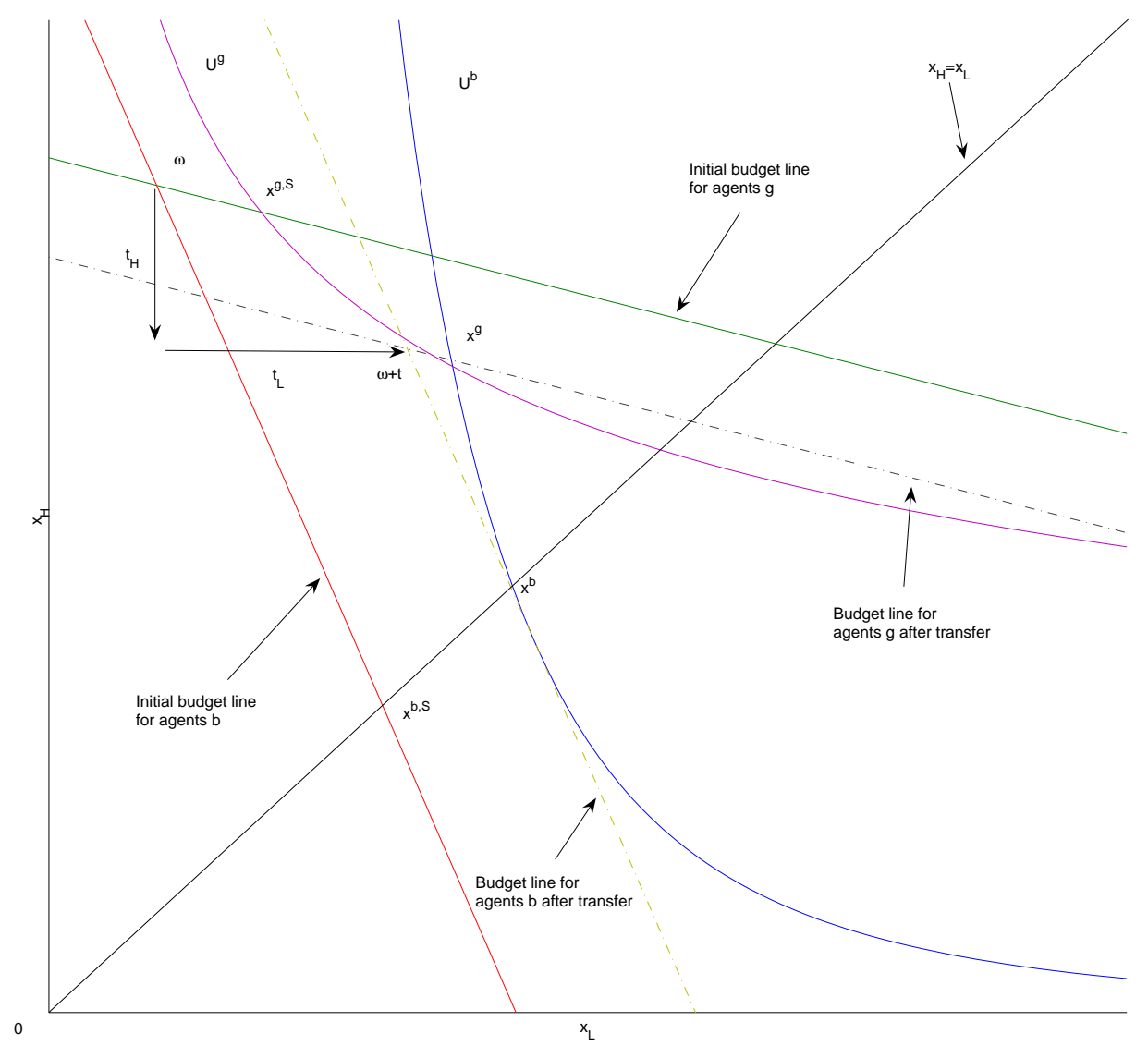

Figure 3: The Second Welfare Theorem. $t=\left\{t_{H}, t_{L}\right\}$ denotes the transfer to the agents, $U^{b}$ and $U^{g}$ the indifference curves of types $b$ and $g$ at the EPT equilibrium after the transfer. The consumption level at the initial EPT equilibrium is $\left(x^{i, S}\right)_{i=g, b}=$ $\left(z^{i, S}\right)_{i=g, b}+\omega$. The consumption at the EPT equilibrium with transfers $t$ is $\left(x^{i}\right)_{i=g, b}=$ $\left(z^{i}\right)_{i=g, b}+\omega$. 


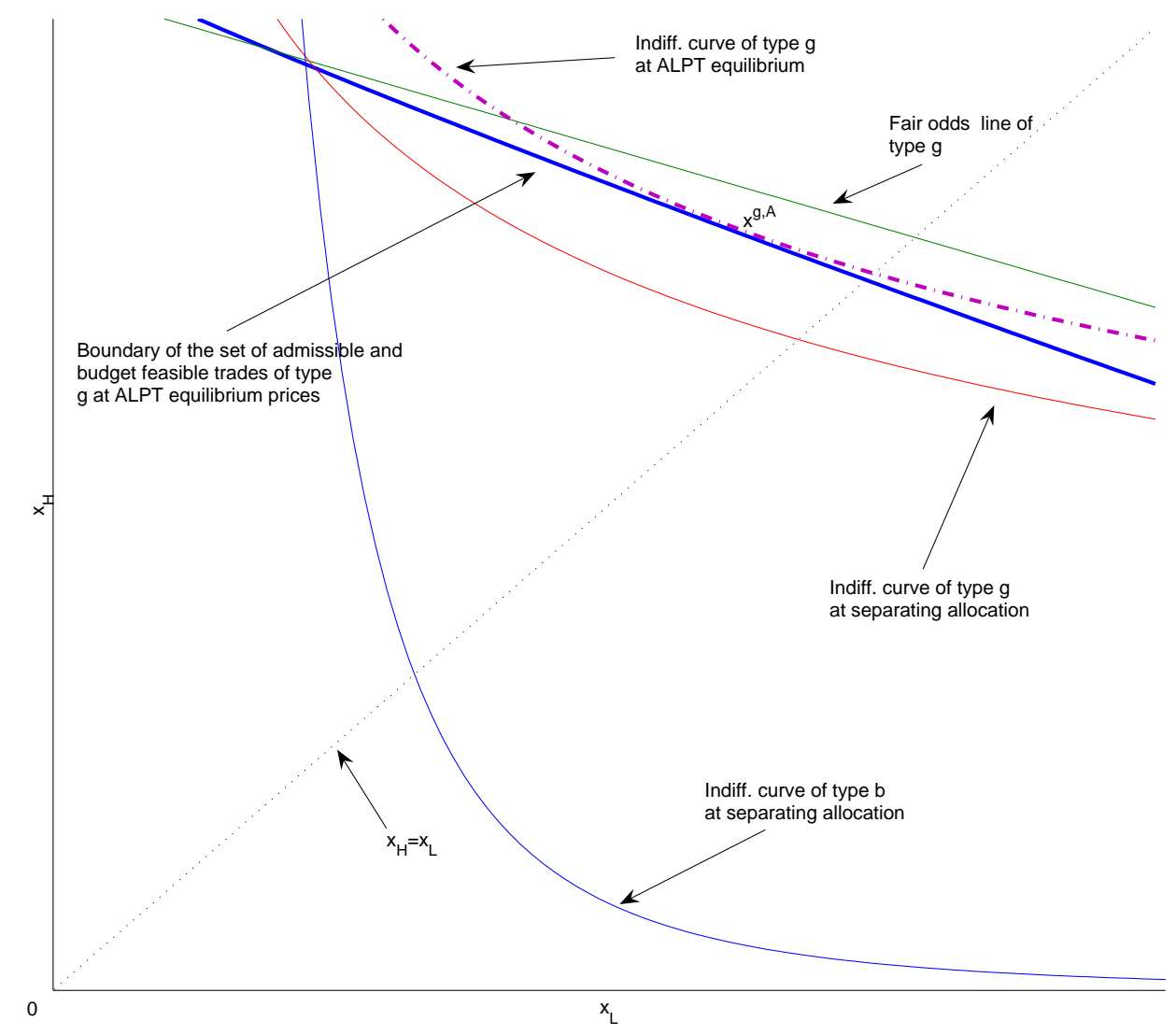

Figure 4: ALPT Equilibrium. $x^{g, A}$ denotes the ALPT equilibrium consumption level for type $g$, while the solid curve depicts the boundary of the set of admissible and budget feasible trades of contingent claims in the market for type $g$ at the equilibrium prices. To find the boundary of this set we proceed as follows. At the prices (11-12), it is immediate to see that the optimal choice of consumption rights for market $g$ is at a full insurance level: $\zeta_{H}(g)+(1-\alpha) \omega_{H}=\zeta_{L}(g)+(1-\alpha) \omega_{L}$. We can then solve this equation, together with the incentive compatibility constraint (ii) in $\mathcal{Z}, \sum_{s \in S} \pi_{s}^{b} u\left(\zeta_{s}(g)+(1-\alpha) \omega_{s}\right)=$ $\sum_{s \in S} \pi_{s}^{b} u\left(z_{g, s}+\omega_{s}\right)$, for $\zeta(g)$ in terms of $z_{g}$. Substituting the resulting expression into the budget constraint in problem $\left(P^{A L P T, g}\right)$, and noting that $z_{b}=0$, for the type $g$ agents, while $p(b)=0$, we obtain an equation whose only variable is $z_{g}$, describing the boundary of the set required. 


\section{CESifo Working Paper Series}

(for full list see www.cesifo-group.de)

1437 Martin Kolmar and Volker Meier, Intra-Generational Externalities and InterGenerational Transfers, March 2005

1438 M. Hashem Pesaran and Takashi Yamagata, Testing Slope Homogeneity in Large Panels, March 2005

1439 Gjermund Nese and Odd Rune Straume, Industry Concentration and Strategic Trade Policy in Successive Oligopoly, April 2005

1440 Tomer Blumkin and Efraim Sadka, A Case for Taxing Education, April 2005

1441 John Whalley, Globalization and Values, April 2005

1442 Denise L. Mauzerall, Babar Sultan, Namsoug Kim and David F. Bradford, Charging $\mathrm{NO}_{x}$ Emitters for Health Damages: An Exploratory Analysis, April 2005

1443 Britta Hamburg, Mathias Hoffmann and Joachim Keller, Consumption, Wealth and Business Cycles in Germany, April 2005

1444 Kohei Daido and Hideshi Itoh, The Pygmalion Effect: An Agency Model with Reference Dependent Preferences, April 2005

1445 John Whalley, Rationality, Irrationality and Economic Cognition, April 2005

1446 Henning Bohn, The Sustainability of Fiscal Policy in the United States, April 2005

1447 Torben M. Andersen, Is there a Role for an Active Fiscal Stabilization Policy? April 2005

1448 Hans Gersbach and Hans Haller, Bargaining Power and Equilibrium Consumption, April 2005

1449 Jerome L. Stein, The Transition Economies: A NATREX Evaluation of Research, April 2005

1450 Raymond Riezman, John Whalley and Shunming Zhang, Metrics Capturing the Degree to which Individual Economies are Globalized, April 2005

1451 Romain Ranciere, Aaron Tornell and Frank Westermann, Systemic Crises and Growth, April 2005

1452 Plutarchos Sakellaris and Focco W. Vijselaar, Capital Quality Improvement and the Sources of Growth in the Euro Area, April 2005

1453 Kevin Milligan and Michael Smart, Regional Grants as Pork Barrel Politics, April 2005 
1454 Panu Poutvaara and Andreas Wagener, To Draft or not to Draft? Efficiency, Generational Incidence, and Political Economy of Military Conscription, April 2005

1455 Maurice Kugler and Hillel Rapoport, Skilled Emigration, Business Networks and Foreign Direct Investment, April 2005

1456 Yin-Wong Cheung and Eiji Fujii, Cross-Country Relative Price Volatility: Effects of Market Structure, April 2005

1457 Margarita Katsimi and Thomas Moutos, Inequality and Relative Reliance on Tariffs: Theory and Evidence, April 2005

1458 Monika Bütler, Olivia Huguenin and Federica Teppa, Why Forcing People to Save for Retirement may Backfire, April 2005

1459 Jos Jansen, The Effects of Disclosure Regulation of an Innovative Firm, April 2005

1460 Helge Bennmarker, Kenneth Carling and Bertil Holmlund, Do Benefit Hikes Damage Job Finding? Evidence from Swedish Unemployment Insurance Reforms, May 2005

1461 Steffen Huck, Kai A. Konrad and Wieland Müller, Merger without Cost Advantages, May 2005

1462 Louis Eeckhoudt and Harris Schlesinger, Putting Risk in its Proper Place, May 2005

1463 Hui Huang, John Whalley and Shunming Zhang, Trade Liberalization in a Joint Spatial Inter-Temporal Trade Model, May 2005

1464 Mikael Priks, Optimal Rent Extraction in Pre-Industrial England and France - Default Risk and Monitoring Costs, May 2005

1465 François Ortalo-Magné and Sven Rady, Heterogeneity within Communities: A Stochastic Model with Tenure Choice, May 2005

1466 Jukka Pirttilä and Sanna Tenhunen, Pawns and Queens Revisited: Public Provision of Private Goods when Individuals make Mistakes, May 2005

1467 Ernst Fehr, Susanne Kremhelmer and Klaus M. Schmidt, Fairness and the Optimal Allocation of Ownership Rights, May 2005

1468 Bruno S. Frey, Knight Fever - Towards an Economics of Awards, May 2005

1469 Torberg Falch and Marte Rønning, The Influence of Student Achievement on Teacher Turnover, May 2005

1470 John Komlos and Peter Salamon, The Poverty of Growth with Interdependent Utility Functions, May 2005 
1471 Hui Huang, Yi Wang, Yiming Wang, John Whalley and Shunming Zhang, A Trade Model with an Optimal Exchange Rate Motivated by Current Discussion of a Chinese Renminbi Float, May 2005

1472 Helge Holden, Lars Holden and Steinar Holden, Contract Adjustment under Uncertainty, May 2005

1473 Kai A. Konrad, Silent Interests and All-Pay Auctions, May 2005

1474 Ingo Vogelsang, Electricity Transmission Pricing and Performance-Based Regulation, May 2005

1475 Spiros Bougheas and Raymond Riezman, Trade and the Distribution of Human Capital, June 2005

1476 Vesa Kanniainen, Seppo Kari and Jouko Ylä-Liedenpohja, The Start-Up and Growth Stages in Enterprise Formation: The "New View" of Dividend Taxation Reconsidered, June 2005

1477 M. Hashem Pesaran, L. Vanessa Smith and Ron P. Smith, What if the UK had Joined the Euro in 1999? An Empirical Evaluation Using a Global VAR, June 2005

1478 Chang Woon Nam and Doina Maria Radulescu, Effects of Corporate Tax Reforms on SMEs' Investment Decisions under the Particular Consideration of Inflation, June 2005

1479 Panos Hatzipanayotou, Sajal Lahiri and Michael S. Michael, Globalization, CrossBorder Pollution and Welfare, June 2005

1480 John Whalley, Pitfalls in the Use of Ad valorem Equivalent Representations of the Trade Impacts of Domestic Policies, June 2005

1481 Edward B. Barbier and Michael Rauscher, Trade and Development in a Labor Surplus Economy, June 2005

1482 Harrie A. A. Verbon and Cees A. Withagen, Tradable Emission Permits in a Federal System, June 2005

1483 Hendrik Hakenes and Andreas Irmen, On the Long-Run Evolution of Technological Knowledge, June 2005

1484 Nicolas Schmitt and Antoine Soubeyran, A Simple Model of Brain Circulation, June 2005

1485 Carsten Hefeker, Uncertainty, Wage Setting and Decision Making in a Monetary Union, June 2005

1486 Ondřej Schneider and Jan Zápal, Fiscal Policy in New EU Member States - Go East, Prudent Man!, June 2005

1487 Christian Schultz, Virtual Capacity and Competition, June 2005 
1488 Yvan Lengwiler and Elmar Wolfstetter, Bid Rigging - An Analysis of Corruption in Auctions, June 2005

1489 Johannes Becker and Clemens Fuest, Does Germany Collect Revenue from Taxing Capital Income?, June 2005

1490 Axel Dreher and Panu Poutvaara, Student Flows and Migration: An Empirical Analysis, June 2005

1491 Bernd Huber and Marco Runkel, Interregional Redistribution and Budget Institutions under Asymmetric Information, June 2005

1492 Guido Tabellini, Culture and Institutions: Economic Development in the Regions of Europe, July 2005

1493 Kurt R. Brekke and Michael Kuhn, Direct to Consumer Advertising in Pharmaceutical Markets, July 2005

1494 Martín Gonzalez-Eiras and Dirk Niepelt, Sustaining Social Security, July 2005

1495 Alfons J. Weichenrieder, (Why) Do we need Corporate Taxation?, July 2005

1496 Paolo M. Panteghini, S-Based Taxation under Default Risk, July 2005

1497 Panos Hatzipanayotou and Michael S. Michael, Migration, Tied Foreign Aid and the Welfare State, July 2005

1498 Agata Antkiewicz and John Whalley, BRICSAM and the Non-WTO, July 2005

1499 Petr Hedbávný, Ondřej Schneider and Jan Zápal, A Fiscal Rule that has Teeth: A Suggestion for a 'Fiscal Sustainability Council' underpinned by the Financial Markets, July 2005

1500 J. Atsu Amegashie and Marco Runkel, Sabotaging Potential Rivals, July 2005

1501 Heikki Oksanen, Actuarial Neutrality across Generations Applied to Public Pensions under Population Ageing: Effects on Government Finances and National Saving, July 2005

1502 Xenia Matschke, Costly Revenue-Raising and the Case for Favoring Import-Competing Industries, July 2005

1503 Horst Raff and Nicolas Schmitt, Why Parallel Trade may Raise Producers Profits, July 2005

1504 Alberto Bisin and Piero Gottardi, Efficient Competitive Equilibria with Adverse Selection, July 2005 